\title{
Investigation of the adiabatic assumption for estimating cloud micro- and macrophysical properties from satellite and ground observations
}

\author{
D. Merk ${ }^{1}$, H. Deneke ${ }^{1}$, B. Pospichal ${ }^{2}$, and P. Seifert ${ }^{1}$ \\ ${ }^{1}$ Leibniz Institute for Tropospheric Research, Leipzig, Germany
}

${ }^{2}$ Leipzig Institute for Meteorology, Leipzig, Germany

Correspondence to: D. Merk (merk@ tropos.de)

Received: 26 January 2015 - Published in Atmos. Chem. Phys. Discuss.: 24 February 2015

Revised: 21 December 2015 - Accepted: 24 December 2015 - Published: 26 January 2016

\begin{abstract}
Cloud properties from both ground-based as well as from geostationary passive satellite observations have been used previously for diagnosing aerosol-cloud interactions. In this investigation, a 2-year data set together with four selected case studies are analyzed with the aim of evaluating the consistency and limitations of current ground-based and satellite-retrieved cloud property data sets. The typically applied adiabatic cloud profile is modified using a subadiabatic factor to account for entrainment within the cloud. Based on the adiabatic factor obtained from the combination of ground-based cloud radar, ceilometer and microwave radiometer, we demonstrate that neither the assumption of a completely adiabatic cloud nor the assumption of a constant sub-adiabatic factor is fulfilled (mean adiabatic factor $0.63 \pm 0.22$ ). As cloud adiabaticity is required to estimate the cloud droplet number concentration but is not available from passive satellite observations, an independent method to estimate the adiabatic factor, and thus the influence of mixing, would be highly desirable for global-scale analyses. Considering the radiative effect of a cloud described by the sub-adiabatic model, we focus on cloud optical depth and its sensitivities. Ground-based estimates are here compared vs. cloud optical depth retrieved from the Meteosat SEVIRI satellite instrument resulting in a bias of -4 and a root mean square difference of 16 . While a synergistic approach based on the combination of ceilometer, cloud radar and microwave radiometer enables an estimate of the cloud droplet concentration, it is highly sensitive to radar calibration and to assumptions about the moments of the droplet size distribution. Similarly, satellite-based estimates of cloud droplet concentration are uncertain. We conclude that neither the ground-
\end{abstract}

based nor satellite-based cloud retrievals applied here allow a robust estimate of cloud droplet concentration, which complicates its use for the study of aerosol-cloud interactions.

\section{Introduction}

Low-level liquid clouds are found in many areas around the globe and play an important role in the energy balance of the Earth. Their microphysical and optical properties are strongly influenced by aerosol particles that act as cloud condensation nuclei. Twomey (1974) first postulated the effect of an increased aerosol number concentration in clouds on the radiative budget, commonly referred to as the first indirect aerosol effect, as a climatically relevant process. The quantification of such aerosol indirect effects remains one of the main uncertainties in climate projections (Boucher et al., 2013). If the liquid water content as well as the geometrical depth of the cloud are considered constant, a higher aerosol load results in an enhanced cloud albedo. This effect is observed in particular by means of ship tracks that form in marine stratocumulus cloud decks, (e.g. Ackerman et al., 2000).

Cloud quantities that are typically used to calculate aerosol-cloud interactions (ACI), are the cloud droplet number concentration $\left(N_{\mathrm{d}}\right)$ and cloud geometrical depth $(H)$. Brenguier et al. (2000) noted that a $15 \%$ change in $H$ can have a similar effect on cloud albedo as a doubling of $N_{\mathrm{d}}$. Han et al. (1998) proposed to investigate a column $N_{\mathrm{d}}$ which is the integral of $N_{\mathrm{d}}$ over $H$. 
While remote sensing observations from ground are always local column measurements, passive satellite observations from, e.g. SEVIRI (Spinning Enhanced Visible and Infrared Imager) or MODIS (Moderate Resolution Imaging Spectrometer), show a good tradeoff in terms of spatiotemporal coverage and are therefore suitable to investigate ACI on a larger scale. Active satellite sensors on the other hand, such as the cloud profiling radar onboard CloudSat (Stephens et al., 2002) or the Cloud-Aerosol-Lidar with Orthogonal Polarization (CALIOP) on-board CALIPSO (Winker et al., 2009, Cloud-Aerosol Lidar and Infrared Pathfinder Satellite Observation), are able to provide vertically resolved cloud observations along their tracks and can be used to investigate aerosol effects on cloud properties, (e.g. Christensen and Stephens, 2011). These lack highly-resolved temporal coverage and have a smaller scanning swath than passive sensors onboard polar-orbiting satellites. Despite their coarser spatial resolution, geostationary satellite observations benefit from the high temporal coverage of up to $5 \mathrm{~min}$ in conjunction with a high spatial coverage. This can be considered as an advantage for the determination of large-scale ACI, since the full daily cycle can be obtained and contrasted to ground-based observations.

If entrainment in clouds leads to a deviation from a linear increasing liquid water content, i.e. sub-adiabatic clouds, the first aerosol effect is not easily observed (Kim et al., 2008). To obtain key quantities from passive satellite observations, the sub-adiabatic cloud model is usually applied, (e.g. Schueller et al., 2003; Boers et al., 2006; Bennartz, 2007). Therefore obtaining cloud adiabaticity is important for the investigation of aerosol-cloud interactions. The combination of ground-based ceilometer and cloud radar is able to provide reliable detection of cloud geometric borders (Boers et al., 2000; Shupe, 2007; Illingworth et al., 2007; Martucci et al., 2010). $N_{\mathrm{d}}$ from ground-based observations can be retrieved from radar-radiometer measurements (Frisch et al., 1995), observations including lidar measurements (Schmidt et al., 2014; Martucci and O'Dowd, 2011), or solar radiation measurements (Dong et al., 1997, 2002). To derive $N_{\mathrm{d}}$ from radar-radiometer observations Rémillard et al. (2013) recently suggested a condensational growth model taking the vertical velocity into account and allowing small variations of $N_{\mathrm{d}}$ with height, while it is assumed vertically constant in most other studies. Due to the under-constrained nature and assumptions made in such retrieval methods, substantial differences for the microphysical properties may occur, as pointed out by Turner et al. (2007), who intercompared several ground-based retrieval methods for one case study. Brandau et al. (2010) showed that the cloud optical depth is less sensitive to the assumptions required in radar-radiometer retrieval approaches and might be considered as an alternative key quantity.

As a consistency check, we contrast key quantities from ground-based remote sensing using a ceilometer, a microwave radiometer and a $35-\mathrm{GHz}$ cloud radar at Leipzig,
Germany $\left(51.35^{\circ} \mathrm{N}, 12.43^{\circ} \mathrm{E}\right)$ and at Krauthausen, Germany $\left(50.897^{\circ} \mathrm{N}, 6.46^{\circ} \mathrm{E}\right)$ with observations from SEVIRI onboard the geostationary satellite Meteosat Second Generation (MSG). Those ground-based instruments are operated in the framework of Cloudnet (Illingworth et al., 2007) and ACTRIS (Aerosols, Clouds and Trace gases Research InfraStructure Network). To our knowledge such evaluations from the SEVIRI instrument for key parameters have been rarely carried out, (e.g. in Roebeling et al., 2008b). Thereby, we discuss the uncertainties introduced by required assumptions when cloud microphysical properties are retrieved, and the effect of different spatiotemporal resolution. As the subadiabatic cloud model is a key concept for the retrievals discussed in this study, we aim to quantify cloud adiabaticity using the available observations.

The paper is structured as follows. In Sect. 2 we introduce the sub-adiabatic model, relevant for the satellite-based retrieval of key parameters, as well as the retrieval methods from ground. Afterwards we describe the instruments and data processing tools used within this study in Sect. 3. In Sect. 4 cloud adiabaticity is investigated. Subsequently we contrast important key properties relevant for ACI from SEVIRI and LACROS (Leipzig Aerosol and Cloud Remote Observations System) and discuss uncertainties from both perspectives (Sect. 5). Finally, a conclusion and outlook is given in Sect. 6.

\section{Cloud retrieval methods using the sub-adiabatic cloud model}

In this section we present the theory of the sub-adiabatic cloud model and retrieval strategies for ground-based instruments as well as passive satellite observations.

For a moist rising air parcel we assume that the liquid water content $q_{\mathrm{L}}(z)$ increases linearly with height (Albrecht et al., 1990):

$q_{\mathrm{L}}(z)=f_{\mathrm{ad}} \Gamma_{\mathrm{ad}}(T, p) z$.

$\Gamma_{\mathrm{ad}}(T, p)$ is the adiabatic rate of increase of liquid water content. The adiabatic factor $f_{\text {ad }}$ can be understood as a reduction of liquid water due to evaporation triggered by the entrainment of drier air masses, which leads to $f_{\text {ad }}<1$ (subadiabatic).

Integrating the liquid water content with height yields the liquid water path $\left(Q_{\mathrm{L}}\right)$. ACI are usually studied as changes in cloud properties and radiative effects for a constant $Q_{\mathrm{L}}$ (Twomey, 1974; Feingold et al., 2003). Therefore we will express all following physical quantities as function of given $Q_{\mathrm{L}}$. Observing $H$ in combination with $Q_{\mathrm{L}}$, and knowing $\Gamma_{\text {ad }}(T, p), f_{\text {ad }}$ can be calculated as follows:

$$
f_{\mathrm{ad}}\left(Q_{\mathrm{L}}, H\right)=\frac{2 Q_{\mathrm{L}}}{H^{2} \Gamma_{\mathrm{ad}}(T, p)} .
$$


The geometrical depth for adiabatic clouds is obtained by resorting to this equation:

$H\left(Q_{\mathrm{L}}, f_{\mathrm{ad}}\right)=\sqrt{\frac{2 Q_{\mathrm{L}}}{f_{\mathrm{ad}} \Gamma_{\mathrm{ad}}}}$.

The equivalent mean volume droplet radius $\left(r_{\mathrm{V}}\right)$ in a cloud depends on $N_{\mathrm{d}}$ and $q_{\mathrm{L}}$ :

$r_{\mathrm{V}}=\sqrt[3]{\frac{3 q_{\mathrm{L}}}{4 \pi \rho_{w} N_{\mathrm{d}}}}$

In the following we assume homogeneous mixing and introduce the effective radius $r_{\mathrm{e}} . r_{\mathrm{e}}$ is defined as the third over the second moment of the droplet size distribution (Hansen and Travis, 1974) and is typically retrieved in remote sensing. $r_{\mathrm{e}}$ is related to the mean volume radius introducing a factor $k_{2}$ that depends on the width of the droplet size distribution (DSD).

$r_{\mathrm{e}}=k_{2}^{-\frac{1}{3}} r_{\mathrm{V}}$

Typical values for $k_{2}$ are 0.67 and 0.8 for marine and continental clouds (Brenguier et al., 2000), respectively. More details on the factor $k_{2}$ for the assumed gamma-size distribution can be found in Appendix A.

By substituting $r_{\mathrm{V}}$ with $r_{\mathrm{e}}$ in Eq. (4), we yield $r_{\mathrm{e}}$ representative for the uppermost cloud layer:

$r_{\mathrm{e}}\left(Q_{\mathrm{L}}, f_{\mathrm{ad}}, N_{\mathrm{d}}\right)=\frac{\sqrt[6]{18 f_{\mathrm{ad}} \Gamma_{\mathrm{ad}} Q_{\mathrm{L}}}}{\sqrt[3]{4 \pi \rho_{w} k_{2} N_{\mathrm{d}}}}$.

To study the microphysical response of aerosols on cloud microphysics with remote sensing techniques, together with $r_{\mathrm{e}}$ the optical depth $\tau$ is often used since both can be easily derived from, e.g. passive satellite observations (Nakajima and King, 1990).

$\tau$ in the sub-adiabatic model can be expressed as a function of $Q_{\mathrm{L}}$ and $r_{\mathrm{e}}$ (Wood, 2006):

$\tau=\frac{9 Q_{\mathrm{L}}}{5 \rho_{w} r_{\mathrm{e}}}$.

Using this equation $Q_{\mathrm{L}}$ can be derived from passive satellite observations. $H$ can be also derived from

$H=\sqrt{\frac{10 \rho_{w} \tau r_{\mathrm{e}}}{9 f_{\mathrm{ad}} \Gamma_{\mathrm{ad}}}}$.

By substituting $r_{\mathrm{e}}$ from Eq. (6), we yield $\tau$ as a function of $Q_{\mathrm{L}}, N_{\mathrm{d}}$ and $f_{\mathrm{ad}}$ :

$\tau\left(Q_{\mathrm{L}}, f_{\mathrm{ad}}, N_{\mathrm{d}}\right)=\frac{9 \sqrt[3]{4 \pi k_{2} N_{\mathrm{d}}} \sqrt[6]{Q_{\mathrm{L}}^{5}}}{5 \sqrt[6]{18 \rho_{w}^{4} f_{\mathrm{ad}} \Gamma_{\mathrm{ad}}}}$.
From this equation, $N_{\mathrm{d}}$ from passive satellite observations can be calculated as follows:

$$
\begin{aligned}
N_{\mathrm{d}}\left(Q_{\mathrm{L}}, f_{\mathrm{ad}}, \tau\right) & =\frac{\sqrt{10 f_{\mathrm{ad}} \Gamma_{\mathrm{ad}} \tau}}{4 \pi k_{2} \sqrt{\rho_{w} r_{\mathrm{e}}^{5}}} \\
& =\frac{20 \rho_{w}^{2} \tau^{3} \sqrt{10 f_{\mathrm{ad}} \Gamma_{\mathrm{ad}}}}{9 \pi k_{2} \sqrt{Q_{\mathrm{L}}^{5}}} .
\end{aligned}
$$

To retrieve $\tau$ and $r_{\mathrm{e}}$ from the given ground-based observations, $N_{\mathrm{d}}$ is substituted in Eq. (6) applying a radarradiometer retrieval approach, (e.g. Fox and Illingworth, 1997; Rémillard et al., 2013, see Appendix A):

$$
N_{\mathrm{d}}\left(Q_{\mathrm{L}}, Z\right)=\frac{9 k_{6} Q_{\mathrm{L}}^{2}}{2 \pi^{2} \rho_{w}^{2}\left(\int_{\mathrm{CBH}}^{\mathrm{CTH}} \sqrt{Z(z)} \mathrm{d} z\right)^{2}} .
$$

Then we find $\tau$ and $r_{\mathrm{e}}$ for given $Q_{\mathrm{L}}$ to depend on the width of the DSD $\left(k_{2}, k_{6}\right), f_{\text {ad }}$ and the integrated radar reflectivity profile $\left(\int Z(z) \mathrm{d} z\right)$. It follows that $\tau \propto\left(k_{2} k_{6}\right)^{\frac{1}{3}}$ and $r_{\mathrm{e}} \propto\left(k_{2} k_{6}\right)^{-\frac{1}{3}}$ (Brandau et al., 2010). Therefore, it would be preferable to derive $N_{\mathrm{d}}$ (zeroth moment) from the 2nd and 3rd moment ( $\tau$ and $Q_{\mathrm{L}}$ ) rather than from the 3rd and 6th moment $\left(Q_{\mathrm{L}}\right.$ and $Z$ ). This is the main reason why $N_{\mathrm{d}}$ in our retrieval is very sensitive to the width of the DSD. The other method would require observations of $\tau$, e.g. from a multifrequency rotating shadowband radiometer (MFRSR).

While in this study homogeneous mixing is assumed, in general two extremes of mixing processes can be considered (Baker et al., 1982; Boers et al., 2006): (a) homogeneous mixing, where $N_{\mathrm{d}}$ stays constant, but the droplet radius $\left(r_{\mathrm{V}}\right)$ is changed due to evaporation, (b) inhomogeneous mixing, where the number of droplets change (dilution of whole droplets), but the droplet radius profile is unchanged. In nature, a mixture of both processes may occur (Lehmann et al., 2009). Without entrainment, we find $f_{\text {ad }}=1$ (adiabatic clouds). The assumption of homogeneous mixing is supported by observations from, Pawlowska et al. (e.g. 2000, 2006). $f_{\text {ad }}$ in this study is considered as representative for the full vertical cloud depth. For such an adiabatic factor $f_{\mathrm{ad}}$ a range of $[0.3,0.9]$ is seen as common (Boers et al., 2006).

Different values for $k_{2}, \Gamma_{\text {ad }}$ and $f_{\text {ad }}$ in Eq. (10) have been considered in previous studies using passive satellites (Table 1) due to various reasons (e.g. different cloud regimes, continental vs. maritime). Often even adiabatic clouds are assumed $\left(f_{\mathrm{ad}}=1\right)$ in the retrieval process, (e.g. Quaas et al., 2006).

\section{Data}

\subsection{Instruments and retrievals}

Satellite data from SEVIRI (Schmetz et al., 2002) is used, which provides 12 spectral channels covering the visible, the 
Table 1. Overview of assumptions made for the sub-adiabatic cloud model applied to derive $N_{\mathrm{d}}$ and $H$ in literature studies. The table lists the values chosen for $\Gamma_{\text {ad }}, f_{\text {ad }}$ (calc. refers to explicitly calculated values from additional data) and $k_{2}$. The table is sorted by publication year starting with the oldest one.

\begin{tabular}{|c|c|c|c|c|c|c|}
\hline Study & Location & Instrument(s) & Derived quantities & $\Gamma_{\mathrm{ad}}\left[\times 10^{-3} \mathrm{~g} \mathrm{~m}^{-4}\right]$ & $f_{\mathrm{ad}}$ & $k_{2}$ \\
\hline Szczodrak et al. (2001) & Eastern Pacific + Southern Ocean & AVHRR & $N_{\mathrm{d}}$ & 2.0 & NA & NA \\
\hline Schüller et al. (2005) & North Atlantic (marine) & MODIS & $N_{\mathrm{d}}, H$ & NA & NA & NA \\
\hline Boers et al. (2006) & Southern Ocean (Cape Grim) & MODIS & $N_{\mathrm{d}}, H$ & const. & 0.6 & 0.87 \\
\hline Quaas et al. (2006, 2008) & Global & MODIS & $N_{\mathrm{d}}$ & 1.9 & 1.0 & 0.8 \\
\hline Bennartz (2007) & Global & MODIS & $N_{\mathrm{d}}, H$ & $T$-dependent & 0.8 & 0.8 \\
\hline Roebeling et al. (2008b) & Europe (continental) & SEVIRI & $N_{\mathrm{d}}, H$ & Boers et al. (2006) & 0.75 & Boers et al. (2006) \\
\hline George and Wood (2010) & Southeast Pacific & MODIS & $N_{\mathrm{d}}$ & 1.95 & NA & NA \\
\hline Painemal and Zuidema (2010) & Southeast Pacific & MODIS & $N_{\mathrm{d}}, H$ & 2.0 & 1.0 & 0.8 \\
\hline Janssen et al. (2011) & Finland (continental) & MODIS & $N_{\mathrm{d}}, H$ & 1.44 & 0.6 & 0.87 \\
\hline Painemal and Zuidema (2011) & Southeast Pacific & MODIS & $N_{\mathrm{d}}$ & 2.0 & 1.0 & 0.8 \\
\hline Min et al. (2012) & Southeast Pacific & MODIS & $N_{\mathrm{d}}, H$ & $T$-dependent & calc. & $0.5-1.0$ \\
\hline Ahmad et al. (2013) & Puijo (continental) & MODIS & $N_{\mathrm{d}}$ & NA & 1.0 & 0.67 \\
\hline Painemal and Zuidema (2013) & Southeast Pacific & MODIS, aircraft & $N_{\mathrm{d}}$ & $T_{\mathrm{cbh}}, p_{\mathrm{cbh}}$ & 0.9 & 0.88 \\
\hline Zeng et al. (2014) & Global & A-Train & $N_{\mathrm{d}}, H$ & $T_{\mathrm{cth}}, p_{\mathrm{cth}}$ & 1.0 & 0.6438 \\
\hline This study & Germany (continental) & SEVIRI & $N_{\mathrm{d}}, H$ & $T_{\mathrm{cbh}}, p_{\mathrm{cbh}}$ & calc. & 0.72 \\
\hline
\end{tabular}

near infrared, and the infrared spectrum. The channels used here have a nadir resolution of $3 \mathrm{~km} \times 3 \mathrm{~km}$, which decreases towards the poles and is about $4 \mathrm{~km} \times 6 \mathrm{~km}$ over our region of interest (central Europe). In this study we use the $5 \mathrm{~min}$ temporal resolution data from the Rapid Scanning Service (RSS). The SEVIRI radiances in the different channels are used as input for the Nowcasting Satellite Application Facility (NWC SAF) algorithm (Derrien, 2012) which provides a cloud mask, cloud top height (CTH), and cloud classification. To obtain the cloud mask, different multispectral tests using SEVIRI channels are applied in order to discriminate cloudy from cloud-free pixels. The cloud top height for low, liquid clouds is obtained by using a best fit between measured brightness temperatures in the $10.8 \mu \mathrm{m}$ channel and simulated values using the RTTOV radiative transfer model (Saunders et al., 1999) applied to atmospheric profiles from the ECMWF (European Centre for Medium-Range Weather Forecasts) numerical weather prediction (NWP) model.

The NWC SAF cloud mask is used in order to derive cloud phase, cloud optical depth, and effective radius with the KNMI (Royal Netherlands Meteorological Institute) cloud physical properties (CPP) algorithm (Roebeling et al., 2006), developed in the context of the satellite application facility on climate monitoring (CM SAF, Schulz et al., 2009). Using a channel in the visible spectrum $(0.6 \mu \mathrm{m})$ together with an absorbing channel in the near infrared $(1.6 \mu \mathrm{m})$ (Nakajima and King, 1990), the CPP algorithm retrieves $\tau$ as well as $r_{\mathrm{e}}$ representative for the uppermost cloud part. As this method relies on solar reflectance channels, it is applied only during daytime.

Also data from MODIS is used within this study. MODIS is an imaging spectrometer onboard the satellites Terra (descending node) and Aqua (ascending node) which probe the Earth's atmosphere from a polar orbit that results in one daytime overpass per satellite per day over the region of interest. MODIS measures in 36 bands in the visible, near-infrared, and infrared spectrum, with some bands having a spatial resolution of up to $250 \mathrm{~m}$. The cloud physical properties (Platnick et al., 2003) are retrieved in a similar manner as for SEVIRI, but at $1 \mathrm{~km}$ spatial resolution using the channels $0.6 \mu \mathrm{m}$ (band 1, over land) and $2.1 \mu \mathrm{m}$ (band 7, over land and sea). In addition, $r_{\mathrm{e}}$ retrievals are available using the channels at $1.6 \mu \mathrm{m}$ (band 6) and $3.7 \mu \mathrm{m}$ (band 20) together with band 1 . Note that band 6 on the Aqua satellite suffers from a stripeproblem (Wang et al., 2006). In this study MODIS collection 6 is used for the retrieved $\tau$ and $r_{\mathrm{e}}$.

The ground-based remote sensing instruments of the Leipzig Aerosol and Cloud Remote Observations System (LACROS) comprise a 35-GHz MIRA-35 cloud radar, a HATPRO (Humidity And Temperature Profiler) microwave radiometer, and a CHM15X ceilometer, which are used also for field campaigns. All instruments are operated in a vertically pointing mode. The raw measurements are processed with the Cloudnet algorithm package (Illingworth et al., 2007). The output data is available at a unified temporal resolution of $30 \mathrm{~s}$ and a vertical grid of $30 \mathrm{~m}$. Cloudnet uses further information such as temperature and pressure profiles from a NWP model (here: COSMO-DE). In this study we use the attenuation-corrected radar reflectivity $Z$ from the cloud radar, $Q_{\mathrm{L}}$ obtained from the microwave radiometer, as well as the cloud base and top height retrieved from ceilometer and cloud radar, respectively. The vertical Doppler velocity from the cloud radar is also utilized. Furthermore Cloudnet provides a target classification applying a series of tests to discriminate cloud phase, drizzle or rain, and aerosols or insects.

\subsection{Data selection}

For this study, we use a 2-year period covering 2012 and 2013. We focus on ideal cases to gain a better understanding of the microphysical processes within the cloud. In order to 

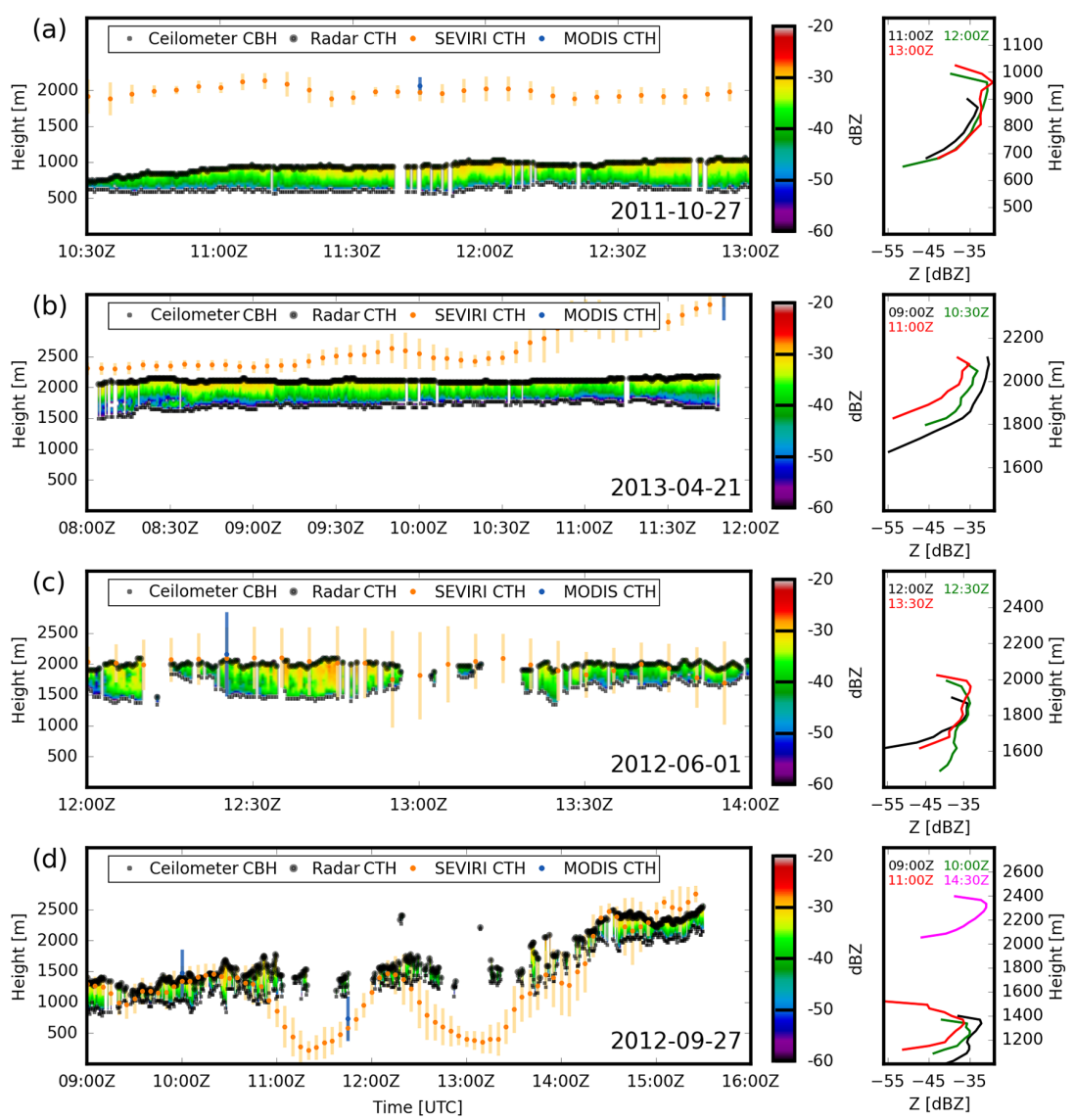

Figure 1. Time series of radar reflectivity $Z(z)$ (in dBZ) and cloud boundaries for the four cases listed in Table 2; (a) 27 October 2011, (b) 21 April 2013, (c) 1 June 2012, (d) 27 September 2012. Cloud borders are shown as detected by Cloudnet with black dots and by SEVIRI using NWC SAF in orange dots, and MODIS in blue dots. Sample profiles of $Z(z)$ are shown at different times during each case.

avoid uncertainties caused by inhomogeneous cloud scenes, such as multi-layer clouds, we consider single-layer cloud systems which are entirely liquid and non-drizzling as ideal.

Cloud profiles as observed from the ground are filtered according to the following conditions.

- There is no occurrence of drizzle/rain in Cloudnet's target classification (and no drizzle/rain in the two nearest neighbour profiles allowed.)

- Values of $Q_{\mathrm{L}}$ are between 25 and $400 \mathrm{~g} \mathrm{~m}^{-2}$. The lower limit is due to typical instrument uncertainty of the microwave radiometer and the upper limit due to typical thresholds for drizzle occurrence (Löhnert et al., 2001).

- The liquid cloud layer must be situated between 300 and $4000 \mathrm{~m}$ above ground.

- The cloud geometrical depth is between 100 and $2000 \mathrm{~m}$.

- There are no ice cloud layers within the first $4000 \mathrm{~m}$ above ground is present. Thin ice cloud layers above are excluded from calculation of $H$. The microwave radiometer is not sensitive to ice, so that $Q_{\mathrm{L}}$ should not be affected.

- No vertical gaps in the cloud layer are present.

$-Z_{\max }<-20 \mathrm{dBZ}$ within the cloud profile to avoid occurrence of drizzle (Rémillard et al., 2013; Mace and Sassen, 2000).

The comparison of optical and microphysical properties between ground-based and MODIS and SEVIRI is only applicable under daytime conditions. Thereby, we have to consider the different spatial and temporal resolution, as well as the different viewing zenith angle on the cloudy scene. For SEVIRI a parallax shift occurs at higher latitudes. The satellite viewing zenith angle for Leipzig is $58.8^{\circ}$. Within this study the average cloud top height is between 1 and $3 \mathrm{~km}$ (see Table 2). This would result in a horizontal displacement of max. $5 \mathrm{~km}$. Greuell and Roebeling (2009) did find a significant difference only for inhomogeneous clouds considering parallax correction. Also taking into account the spatial resolution of SEVIRI over central Europe of $4 \mathrm{~km} \times 6 \mathrm{~km}$, 
Table 2. Cases used within this study sorted by date. The minimum cloud base height $(\mathrm{CBH})$ and the maximum cloud top height $(\mathrm{CTH})$ of the liquid cloud layer investigated are presented together with the temporally averaged inhomogeneity parameter $(\chi)$ as in Cahalan et al. (1994) calculated from $\tau$ of the \pm 2 surrounding SEVIRI pixels for each observation time. Furthermore the category for each case is listed.

\begin{tabular}{lrlrrrl}
\hline Date & Time & Location & $\operatorname{Min}(\mathrm{CBH})[\mathrm{m}]$ & $\operatorname{Max}(\mathrm{CTH})[\mathrm{m}]$ & $\chi$ & category \\
\hline 27 Oct 2011 & $10: 30-13: 00$ UTC & Leipzig & $526 \mathrm{~m}$ & $1056 \mathrm{~m}$ & 0.96 & homogeneous \\
1 Jun 2012 & $12: 00-14: 00$ UTC & Leipzig & $1336 \mathrm{~m}$ & $2085 \mathrm{~m}$ & 0.85 & inhomogeneous \\
27 Sep 2012 & $09: 00-16: 00$ UTC & Leipzig & $775 \mathrm{~m}$ & $2553 \mathrm{~m}$ & 0.87 & inhomogeneous \\
21 Apr 2013 & $08: 00-12: 00$ UTC & Krauthausen & $1485 \mathrm{~m}$ & $2171 \mathrm{~m}$ & 0.99 & homogeneous \\
\hline
\end{tabular}

we decided to neglect the parallax correction for our study, instead we consider surrounding pixels. For SEVIRI a field of $3 \times 3$ pixels (case studies), and $5 \times 5$ pixels (longer-term statistics) centred on the ground site is used and spatially averaged.

We will furthermore present four hand-selected cases to highlight specific problems more closely. For the four case days, we calculate the spatial inhomogeneity parameter following Cahalan et al. (1994), using the $3 \times 3$ SEVIRI pixel field, which can be interpreted also in terms of temporal inhomogeneity $(\chi)$ if advection of clouds over a fixed location is considered:

$\chi=\frac{\exp (\overline{\ln \tau})}{\bar{\tau}}$

A short overview of the case characteristics is given in Table 2 . The cloud boundaries are shown along with the $Z$ profile in Fig. 1. The synoptic conditions for the cases are as follows. A high pressure system dominates the synoptic weather pattern on 21 October 2011 (Fig. 1a). The temperature at the $850 \mathrm{hPa}$ pressure level over Leipzig is around $5^{\circ} \mathrm{C}$. Therefore the stratocumulus cloud layer that is observed between 10:30 and 13:00 Z consists entirely of water droplets. Its geometrical depth increases in the beginning of the observation period. The weather pattern on 21 April 2013 (Fig. 1b) is quite similar with the high pressure influence being stronger. The temperatures at the $850 \mathrm{hPa}$ pressure level are slightly positive. During the whole observation period at Krauthausen a closed cloud deck is visible. The ground-obtained cloud top height shows only small variability, while the ceilometerderived cloud base is more inhomogeneous during the beginning of the observation period. A thin overlying cirrus cloud deck can be observed around 10:00 Z and between 11:00-12:00 Z. An upper-level ridge covers central Europe on 1 June 2012 (Fig. 1c), but the area around Leipzig is also influenced by a surface low. Temperatures at $850 \mathrm{hPa}$ lie around $10^{\circ} \mathrm{C}$. The stratocumulus cloud deck with the cloud tops slightly below $2000 \mathrm{~m}$ between 12:00 and 14:00 Z is broken. The weather pattern for the 27 September 2012 (Fig. 1d) shows Leipzig directly in front of a well pronounced trough. Temperatures at $850 \mathrm{hPa}$ lie again around $10^{\circ} \mathrm{C}$ and the cloud types vary between stratocumulus and shallow cumulus. The cloud base height increases throughout the day.

\section{Cloud adiabaticity}

Entrainment of dry air into the clouds leads to evaporation of cloud water and therefore to a deviation from the adiabatic liquid water content profile. Knowledge of $f_{\text {ad }}$ is required to calculate key quantities for investigating ACI from passive satellite observations. Therefore we first study cloud adiabaticity, before conducting a intercomparison of groundbased and satellite key properties as well as discuss sources of its uncertainties. $f_{\text {ad }}$ can be calculated from the groundbased observations. We will further investigate possibilities to estimate it from passive satellite observations.

\subsection{Adiabatic factor from ground-based observations}

The ground-based $f_{\text {ad }}$ is calculated using $Q_{\mathrm{L}}$ from the microwave radiometer, $H$ as the difference of cloud top height from the cloud radar and cloud base height from the ceilometer, and $\Gamma_{\mathrm{ad}}\left(T_{\mathrm{cbh}}, p_{\mathrm{cbh}}\right)$ using NWP data in Eq. (2).

Boers et al. (2006) suggests a range of typical values of $[0.3,0.9]$. We omitted adiabatic factors with $f_{\text {ad }}>1.0$ since those are most likely affected by the measurement uncertainties, since the occurrence of "superadiabatic" cloud profiles in nature is physically implausible. Such artefacts especially arise due to uncertainties in $Q_{\mathrm{L}}$ and $H$ for thin clouds. In contrast to the original Cloudnet code, our calculation of $f_{\text {ad }}$ allows for values greater than 1.0. Within Cloudnet "superadiabatic" profiles are avoided by increasing the cloud top height if the integrated adiabatic $q_{\mathrm{L}}$ is smaller than $Q_{\mathrm{L}}$ measured by the microwave radiometer.

An example time series for one case (21 April 2013) is shown in Fig. 2 (see the Supplement for more cases). For this case we find values of $f_{\text {ad }}$ between 0.2 and 0.6 before 09:00 UTC. Measurements of $Z$ (Fig. 1b) reveal that the cloud base is more inhomogeneous during this time period than later on. After 09:00 UTC, $f_{\text {ad }}$ varies between 0.5 and 1.0 .

From Fig. 3a we find a mean of $f_{\text {ad }}=0.63$ and the interquartile range (IQR) as $[0.46,0.81]$ for the entire data set covering 2012 and 2013. This corresponds well with the typical value of 0.6 given by Boers et al. (2006). Overall, there is a large spread of values covering the full physical meaningful range from 0 to 1 (mean values for individual cases as presented in Fig. 1 are listed in Table 4). $f_{\text {ad }}$ not only 
Table 3. Uncertainty estimation for $N_{\mathrm{d}}$ and $\tau$ by varying $Z, Q_{\mathrm{L}}$ and the effective variance of the gamma distribution $v$. Relative uncertainties are given in brackets. Case 1: 21 April 2013, 11:00 UTC. $Q_{\mathrm{L}}=69 \mathrm{~g} \mathrm{~m}^{-2}, H=311 \mathrm{~m}, f_{\mathrm{ad}}=0.76$. Retrieved values: $N_{\mathrm{d}}=456 \mathrm{~cm}^{-3}$ applying $v=0.1, \tau=18$. Case 2: 1 June 2012, 13:30 UTC. $Q_{\mathrm{L}}=62 \mathrm{~g} \mathrm{~m}^{-2}, H=342 \mathrm{~m}, f_{\mathrm{ad}}=0.55, N_{\mathrm{d}}=216 \mathrm{~cm}^{-3}, \tau=13.6$.

\begin{tabular}{lrrrr}
\hline & $\Delta N_{\mathrm{d}}($ case 1$)$ & $\Delta N_{\mathrm{d}}($ case 2$)$ & $\Delta \tau($ case 1) & $\Delta \tau$ (case 2) \\
\hline$\Delta Z=-2 \mathrm{dBZ}$ & $266(58 \%)$ & $126(58 \%)$ & $3.0(17 \%)$ & $2.3(17 \%)$ \\
$\Delta Z=+2 \mathrm{dBZ}$ & $168(37 \%)$ & $80(37 \%)$ & $2.6(14 \%)$ & $1.9(14 \%)$ \\
$\Delta Q_{\mathrm{L}}=-25 \mathrm{~g} \mathrm{~m}^{-2}$ & $267(59 \%)$ & $140(64 \%)$ & $4.7(26 \%)$ & $6.8(49 \%)$ \\
$\Delta Q_{\mathrm{L}}=+25 \mathrm{~g} \mathrm{~m}^{-2}$ & $384(84 \%)$ & $209(96 \%)$ & $4.1(22 \%)$ & $7.8(57 \%)$ \\
$v=0.200$ & $614(135 \%)$ & $292(135 \%)$ & $2.9(16 \%)$ & $2.2(16 \%)$ \\
$\nu=0.043$ & $174(38 \%)$ & $83(38 \%)$ & $1.7(9 \%)$ & $1.3(9 \%)$ \\
\hline
\end{tabular}

Table 4. Median and standard deviation of $f_{\text {ad }}$ (calculated from Eq. 2) for individual cases. Furthermore the median of $f_{\text {ad }}$, classified into updraft $(v \geq 0)$ and downdraft $(v<0)$ regimes, as well as the fraction of sub-adiatic cloud profiles is shown. Values of $f_{\text {ad }}>1.0$ are omitted because those are likely affected by measurement uncertainties.

\begin{tabular}{lrrrr}
\hline & 21 Apr 2013 & 27 Sep 2012 & 27 Oct 2011 & 1 Jun 2012 \\
\hline Median $f_{\text {ad }}$ & 0.63 & 0.62 & 0.70 & 0.44 \\
SD $f_{\text {ad }}$ & 0.18 & 0.21 & 0.12 & 0.24 \\
\hline Median $f_{\text {ad }}[v \geq 0]$ & 0.78 & 0.64 & 0.76 & 0.44 \\
$\operatorname{SD~} f_{\text {ad }}[v \geq 0]$ & 0.21 & 0.20 & 0.12 & 0.23 \\
Median $f_{\text {ad }}[v \leq 0]$ & 0.61 & 0.62 & 0.66 & 0.44 \\
$\operatorname{SD~} f_{\text {ad }}[v \leq 0]$ & 0.17 & 0.21 & 0.10 & 0.24 \\
\hline Fraction $f_{\text {ad }}<1$ & 0.99 & 0.79 & 0.99 & 0.90 \\
\hline
\end{tabular}

changes from case to case, but also varies with time for individual days, reflecting the natural variability of entrainment processes. The variability of $f_{\text {ad }}$ is larger for the inhomogeneous cases than for the homogeneous ones (Table 4), but the range of values is similar. This shows that independent from temporal cloud homogeneity the majority of clouds seems to be sub-adiabatic. Therefore considering a constant $f_{\text {ad }}$ like in previous studies (Table 1) could affect retrievals of cloud properties.

When looking for proxies for $f_{\mathrm{ad}}$, we find a tendency that geometrically thicker clouds are less adiabatic (Fig. 3b). Already Warner (1955) found a decrease in $f_{\text {ad }}$ with height. It also supports the findings of Min et al. (2012), who observed the tendency that thicker clouds are less adiabatic in the Southeast Pacific. Mainly the thin clouds $(H<400 \mathrm{~m})$ result in $f_{\mathrm{ad}}>1$, as also found by Miller et al. (1998), and therefore the investigation of such thin clouds remains challenging.

Schmidt et al. (2014) used observations of two cases with temporally homogeneous stratocumulus clouds over Leipzig, Germany, and found that in case of updrafts in clouds, the $q_{\mathrm{L}}$ profile tends to be more adiabatic. To investigate if such a behaviour also occurs for our cases we apply the cloud radar Doppler velocity at the cloud base. The average vertical velocity at cloud base for all samples in 2012 and 2013 is found to be $-0.1 \mathrm{~m} \mathrm{~s}^{-1}$ with the majority of points $(93 \%)$ in the range $[-1,1] \mathrm{m} \mathrm{s}^{-1}$. Considering the vertical velocity as

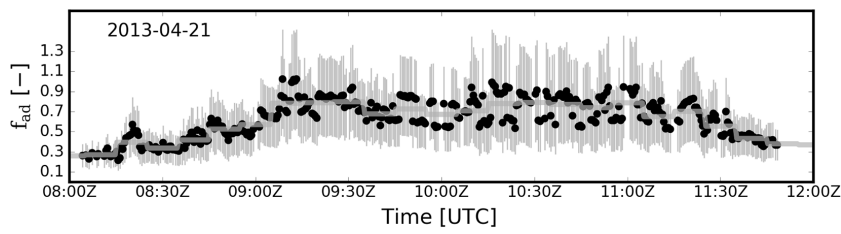

Figure 2. Time series of the adiabatic factor $f_{\text {ad }}$ for 21 April 2013. Black dots represent $f_{\text {ad }}$ derived using ground-based $H$ and $Q_{\mathrm{L}}$. The gray line represents the $10 \mathrm{~min}$ averaged and interpolated $f_{\mathrm{ad}}$ neglecting superadiabatic values.

function of $f_{\text {ad }}$ (Fig. 3c) we find a large spread, which makes it difficult to detect a distinct influence of updraft speed on cloud adiabaticity. However, the notch around the median in the box-whisker plot does not overlap for updraft and downdraft regimes. According to Krzywinski and Altman (2014) the median can be judged to differ significantly on the $95 \%$ confidence interval if there is no overlay in the notches. We further calculate the median $f_{\text {ad }}$ for updraft and downdraft regimes for the four selected cases, and find for three out of four cases that clouds are slightly more adiabatic in the updraft regime (Table 4). This behaviour is expected from adiabaticity and also supported by the findings of Schmidt et al. (2014). They report that this effect is strongest at the cloud base and blurs when the data points are averaged over the whole cloud profile. 

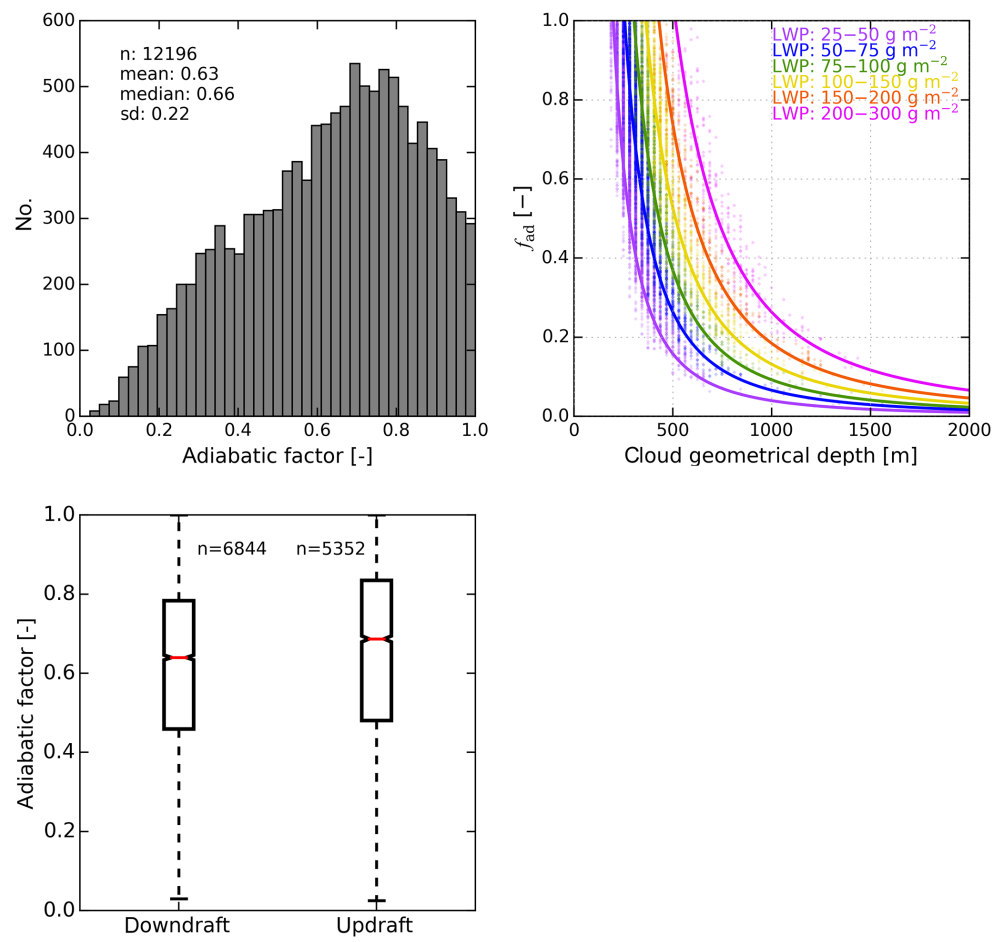

Figure 3. (a) Histogram of $f_{\text {ad }}$ in 2012 and 2013 at LACROS. (b) $f_{\text {ad }}$ as a function of observed $H$. Colours indicate different $Q_{\mathrm{L}}$ bins. The solid lines represent the relationship described in Eq. (2) for bin mean $Q_{\mathrm{L}}$ and $\Gamma_{\mathrm{ad}}=1.9 \times 10^{-3} \mathrm{~g} \mathrm{~m}^{-4}$. (c) $f_{\text {ad }}$ separated by up- and downdraft at the cloud base.

\subsection{Adiabatic factor from satellite observations}

From ground-based observations we can show that $f_{\text {ad }}$ is highly variable even for one location. Therefore we can also expect strong variability for cloud regimes over different regions observed by satellite (e.g. maritime vs. continental). To obtain ACI key quantities from passive satellite observations, $f_{\text {ad }}$ is required over a larger domain. The German weather service (DWD) operates a ceilometer network (Flentje et al., 2010) which can be used to obtain the cloud base height (CBH). The question remains if $Q_{\mathrm{L}}$ and CTH from SEVIRI are accurate enough to allow for an estimate of the adiabatic factor using Eq. (2). To address this question, we contrast $Q_{\mathrm{L}}$ and CTH obtained from SEVIRI with LACROS.

We investigate liquid clouds in a 2 -year period covering 2012 and 2013. Since the estimate of $f_{\text {ad }}$ from passive satellite observations is expected to be applied over a larger domain, it should be independent from ground-based information. Therefore the sampling is now done in terms of satellite observed quantities. An area of $5 \times 5$ pixels (total of 25 pixels) centred at the location of LACROS is considered for each available SEVIRI observation. For this pixel field we obtain average, standard deviation of CTH and the liquid cloud fraction. The liquid fraction is determined by the cloud type classification for each pixel from CPP. We require $90 \%$ of the pixel field ( 23 out of 25 pixels) to be classified as pure liquid clouds. As additional constraint, the standard deviation of CTH for the 25 pixels has to be smaller than $400 \mathrm{~m}$. For LACROS we use the observation averaged using a window of $10 \mathrm{~min}$ around the SEVIRI observation time. No requirements regarding the cloud phase are made for LACROS.

We first look at the $\mathrm{CTH}$, which can be compared at daytime and night-time. The ground-based instruments give the actual geometrical CTH while from passive satellites a radiative CTH is obtained. Ignoring this physical difference we can see that the SEVIRI CTH is positively biased (Fig. 4a). Derrien et al. (2005) reports a very similar overestimation $(320 \mathrm{~m})$ with a large standard deviation of $1030 \mathrm{~m}$ for low, opaque clouds. Considering the central pixel of the field does not change the result significantly, showing that the cloud fields are rather homogeneous and should therefore be suitable for such a comparison. The observed bias is not explained by the limited vertical step size of $200 \mathrm{~m}$ in the SEVIRI CTH product. A likely explanation of this bias is found in the representation of inversions. Splitting the sample by model inversions did not provide significantly better results, but the actual inversions might not be well represented by the model. Such a case can be seen for 27 October 2011. There, the CTH is roughly $1000 \mathrm{~m}$ lower than for the other three cases presented here, but the retrieved satellite CTH lies at $2000 \mathrm{~m}$. Considering the closest radiosounding of Lindenberg (Germany), we find two inversion layers on top of each other between 900 and $3000 \mathrm{~m}$, which results in ambiguities in finding the correct cloud height. Differences may also re- 
sult from semitransparent cirrus cloud layers (21 April 2013), or broken cloud conditions (1 June and 27 September 2012).

For the comparison of $Q_{\mathrm{L}}$ we impose the condition that the values are between 20 and $400 \mathrm{~g} \mathrm{~m}^{-2}$. The comparison can only be applied during daytime. Both requirements reduce the number of samples by $56 \%$ compared to the CTH sample. The difference of $Q_{\mathrm{L}}$ has a distribution with a distinct peak close to zero (Fig. 4c). There is a small negative bias of $-21 \mathrm{~g} \mathrm{~m}^{-2}$, which is within the uncertainty range of the ground-based measurements, not even considering the uncertainty of the satellite-based estimate. Similar to the CTH comparison we see that the distribution of the central pixel is not significantly different from the field average, although the spread is larger. The distribution and the standard deviation are consistent with the observations in the validation study of Roebeling et al. (2008b) for the Cloudnet stations of Chilbolton and Palaiseau. Similar to their study we see a slight negative skewness, which stems from larger $Q_{\mathrm{L}}$ values seen from the ground-based microwave radiometer. Roebeling et al. (2008b) also reported that accuracy is reduced for higher $Q_{\mathrm{L}}$ values. Further possible explanations for differences in $Q_{\mathrm{L}}$ observed from ground and SEVIRI can be found in remaining cloud inhomogeneities and sampling differences. Generally, unfavourable viewing angles that occur especially in winter conditions can lead to large uncertainties in the satellite retrieval. In our sample the majority of the cases occur in summer months (April to September, 80\%). Looking at specific case days, we find the mean difference of $Q_{\mathrm{L}}$ for two homogeneous cases between SEVIRI and the ground-based microwave radiometer in reasonable agreement $\left(8 \mathrm{~g} \mathrm{~m}^{-2}(10 \%)\right.$ for 21 April 2013, $25 \mathrm{~g} \mathrm{~m}^{-2}$ (32\%) for 27 October 2011), while there are larger differences for two inhomogeneous cases $\left(50 \mathrm{~g} \mathrm{~m}^{-2}(87 \%)\right.$ for 1 June 2012 and $33 \mathrm{~g} \mathrm{~m}^{-2}(80 \%)$ for 27 September 2012).

A similar study by Meerkötter and Zinner (2007) found a standard deviation of $369 \mathrm{~m}$ between satellite-based adiabatic $\mathrm{CBH}$ and ceilometer $\mathrm{CBH}$. They applied CTH and $Q_{\mathrm{L}}$ from AVHRR (Advanced Very High Resolution Radiometer) and assumed adiabatic clouds to compare the spatially and temporally averaged satellite product. The same comparison between SEVIRI and radiosonde observations resulted in a standard deviation of $\pm 290 \mathrm{~m}$ (Meerkötter and Bugliaro, 2009). They suggest that this method can be applied for convective clouds in their early growth stage, which are located near the condensation level. Their sample is focused on relatively thin water clouds $(\sim 250 \mathrm{~m})$, which are more likely close to adiabaticity according to our Fig. 3b. As we will discuss in the following the adiabatic factor for such thin clouds is very sensitive to errors in $H$, so that an instantaneous retrieval of $f_{\text {ad }}$ is not feasible.

\subsection{Uncertainty estimate of $f_{\text {ad }}$}

To investigate the uncertainties that influence the calculation of $f_{\text {ad }}$, we consider an adiabatic cloud $\left(f_{\mathrm{ad}}=1\right)$ with $Q_{\mathrm{L}}=$
$100 \mathrm{~g} \mathrm{~m}^{-2}$ and $H=324 \mathrm{~m}$ and $\Gamma_{\text {ad }}=1.9 \times 10^{-3} \mathrm{~g} \mathrm{~m}^{-4}$. The $Q_{\mathrm{L}}$ retrieval uncertainty (microwave radiometer instrument error + retrieval error) is approximately $25 \mathrm{~g} \mathrm{~m}^{-2}$ and the vertical resolution of the ceilometer and the cloud radar results in at least $\pm 60 \mathrm{~m}$ uncertainty of $H$. Accounting for the maximum uncertainty $\left(Q_{\mathrm{L}}=125 \mathrm{~g} \mathrm{~m}^{-2}\right.$, and $\left.H_{\text {obs }}^{\text {ground }}=264 \mathrm{~m}\right)$ or $\left(Q_{\mathrm{L}}=75 \mathrm{~g} \mathrm{~m}^{-2}\right.$ and $\left.H_{\mathrm{obs}}^{\text {ground }}=384 \mathrm{~m}\right)$, the resulting $f_{\mathrm{ad}}$ would be 1.89 or 0.54 , respectively. This shows that with the current uncertainty limits of the ground-based observations $f_{\text {ad }}$ is still prone to large uncertainties especially for geometrically thin clouds.

If we consider the root mean square differences (RMSD) of the comparison of ground and satellite-based values with $\Delta Q_{\mathrm{L}}=67 \mathrm{~g} \mathrm{~m}^{-2}$ and $\Delta \mathrm{CTH}=1174 \mathrm{~m}$, we can clearly see that especially the observed bias in $\mathrm{CTH}$ can result in large uncertainties of an instantaneous estimate of $f_{\text {ad }}$ especially for thin clouds. For the adiabatic cloud considered above, this RMSDs result in a relative uncertainty for the adiabatic factor of $727 \%$, neglecting uncertainties at the CBH. Even considering a cloud that is twice as thick, the relative uncertainty is still $362 \%$. This shows that subsampling the SEVIRI observations to homogeneous, liquid clouds does still show differences when compared to a ground-based reference that are too large to estimate $f_{\text {ad }}$ with sufficient reliability, mainly due to uncertainties in the $\mathrm{CTH}$ product. With this approach using $Q_{\mathrm{L}}$ and $H$ we cannot determine the adiabaticity of clouds with a reasonable accuracy. Therefore we will have a look at the microphysical quantities.

\section{Microphysical key quantities relevant for ACI}

$H$ and $N_{\mathrm{d}}$ are used as the main parameters in many investigations of ACI as both cloud properties have a direct effect on cloud albedo. Due to the required assumptions about the DSD, a retrieval of $N_{\mathrm{d}}$ from a radar-radiometer approach remains highly uncertain. Brandau et al. (2010) follows an alternative approach to retrieve $\tau$ instead of $N_{\mathrm{d}}$ and demonstrated it to be less sensitive to the assumption of the width of the DSD.

In the following, we will cross-check key quantities $H$ and $\tau$ from ground and satellite. We will also discuss the effect of uncertainties in our observations for the sub-adiabatic cloud model on $N_{\mathrm{d}}, \tau$ and $H$.

\subsection{Cloud geometrical depth $H$ intercomparison from space and ground}

Contrasting SEVIRI $H$ (Eq. 3, using $f_{\text {ad }}$ from ground-based observations) with the LACROS $H$, we are able to investigate the same quantity obtained with two independent physical retrieval approaches.

The correlation coefficient is 0.89 for 21 April 2013, 0.70 for 27 October 2011, 0.38 for 1 June 2012, and 0.45 for 27 September 2012 and increases by 10, 39, 118, and $71 \%$ 

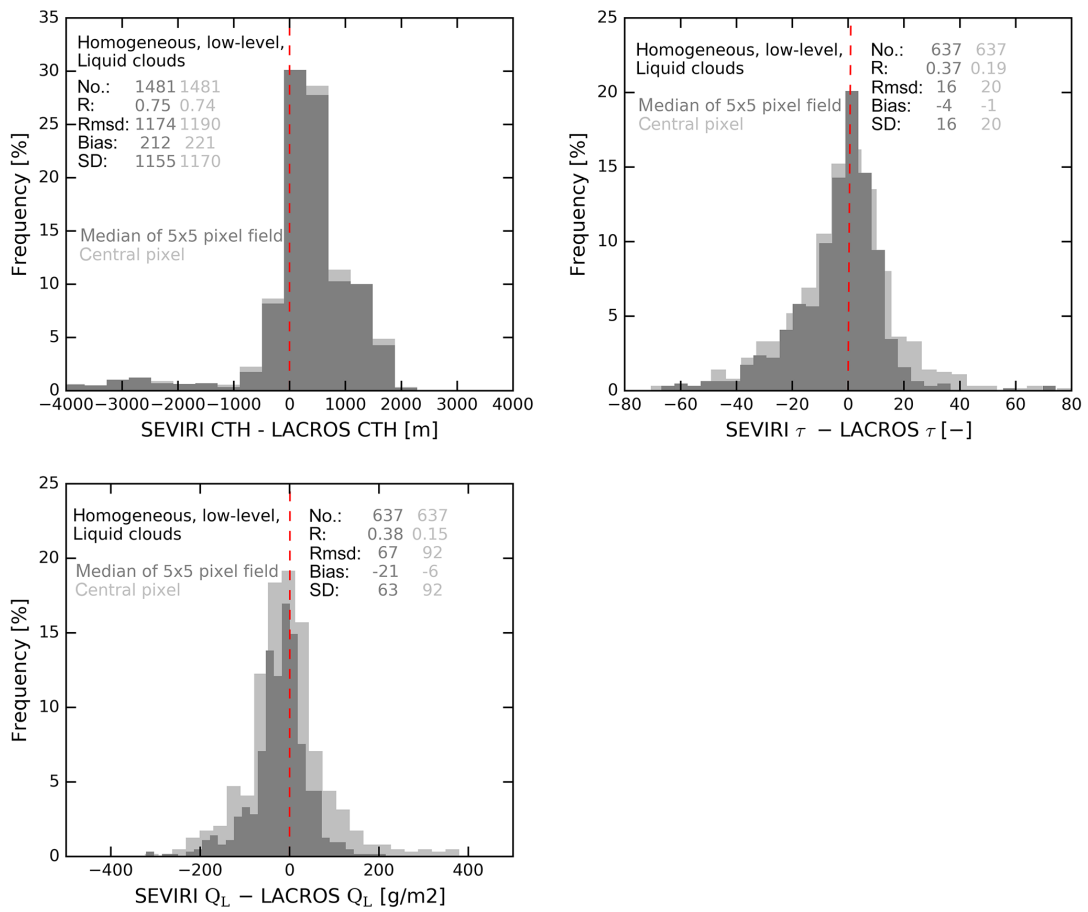

Figure 4. Histogram of differences between SEVIRI and LACROS derived cloud properties for 2012 and 2013: (a) cloud top height (CTH), (b) cloud optical depth $(\tau)$, (c) liquid water path $\left(Q_{\mathrm{L}}\right)$. Median of $5 \times 5$ SEVIRI pixels centred at LACROS (dark gray), closest pixel to LACROS (light gray). Zero difference is marked by a dashed red line.

for $30 \mathrm{~min}$ temporal averaging, respectively (see Table 5). The improvement of correlation is not surprising when comparing averaged data, (e.g. Deneke et al., 2009; McComiskey and Feingold, 2012). However, a longer averaging period removes the original variability of the data. The correlation for temporally averaged data is within the range of values that were obtained by Roebeling et al. (2008b), Min et al. (2012) and Painemal and Zuidema (2010). Roebeling et al. (2008b) found correlations of 0.71 between SEVIRI and Cloudnet for a homogeneous stratocumulus cloud layer. Min et al. (2012) found correlations of 0.62 between in situ and MODIS retrieved $H$, and could show a better agreement of $H$ when $f_{\text {ad }}$ is explicitly calculated and considered. Painemal and Zuidema (2010) found correlations of 0.54 ( 0.7 for $H<400 \mathrm{~m}$ with cloud fraction $>90 \%$ ) comparing radiosonde-derived $H$ to respective MODIS observations. In their study Painemal and Zuidema (2010) reported that satellite values were higher compared to the ground-based ones. The reason for this can potentially be explained by a bias of MODIS-retrieved $r_{\mathrm{e}}$ but also in the choice of $f_{\text {ad }}$ in the retrieval of $H$.

\subsection{Cloud optical depth $\tau$ intercomparison from space and ground}

The intercomparison of SEVIRI with LACROS retrieved $\tau$ results in differences of $2.3(8 \%)$ for 21 April 2013, 3.6
Table 5. Correlation coefficient of $H$ from LACROS and from SEVIRI ( $3 \times 3$ pixel spatial average) for different temporal averaging periods applied to both data sets.

\begin{tabular}{lrrr}
\hline Date & 5 min average & 10 min average & 30 min average \\
\hline 21 Apr 2013 & 0.89 & 0.96 & 0.98 \\
27 Oct 2011 & 0.70 & 0.72 & 0.97 \\
27 Sep 2012 & 0.45 & 0.61 & 0.77 \\
1 Jun 2012 & 0.38 & 0.53 & 0.83 \\
\hline
\end{tabular}

(21\%) for 27 October 2011, 9.3 (76\%) for 1 June 2012 and $8.0(61 \%)$ for 27 September 2012. The higher resolution of the ground-based observations leads to larger variability also for the homogeneous cases. The median conditions result in a good fit to the satellite ( $\tau, Q_{\mathrm{L}}$ )-pairs (Fig. 5) for the homogeneous case on 21 April 2013. For this case the satellite pairs are also within the ground-based temporal IQR. The situation is similar even for the inhomogeneous case on 1 June 2012. The situation turns out to be more complicated when looking at the inhomogeneous case on 27 September 2012. Overall satellite $\tau$ and $Q_{\mathrm{L}}$ show lower values, which result likely due to broken-cloud effects in the SEVIRI retrieval. For broken clouds within the SEVIRI pixel the satellite receives a combined signal from the clouds but also from the surface. Such moving, broken cloud fields result in a smoother temporal pattern from the satellite perspective. From the time- 

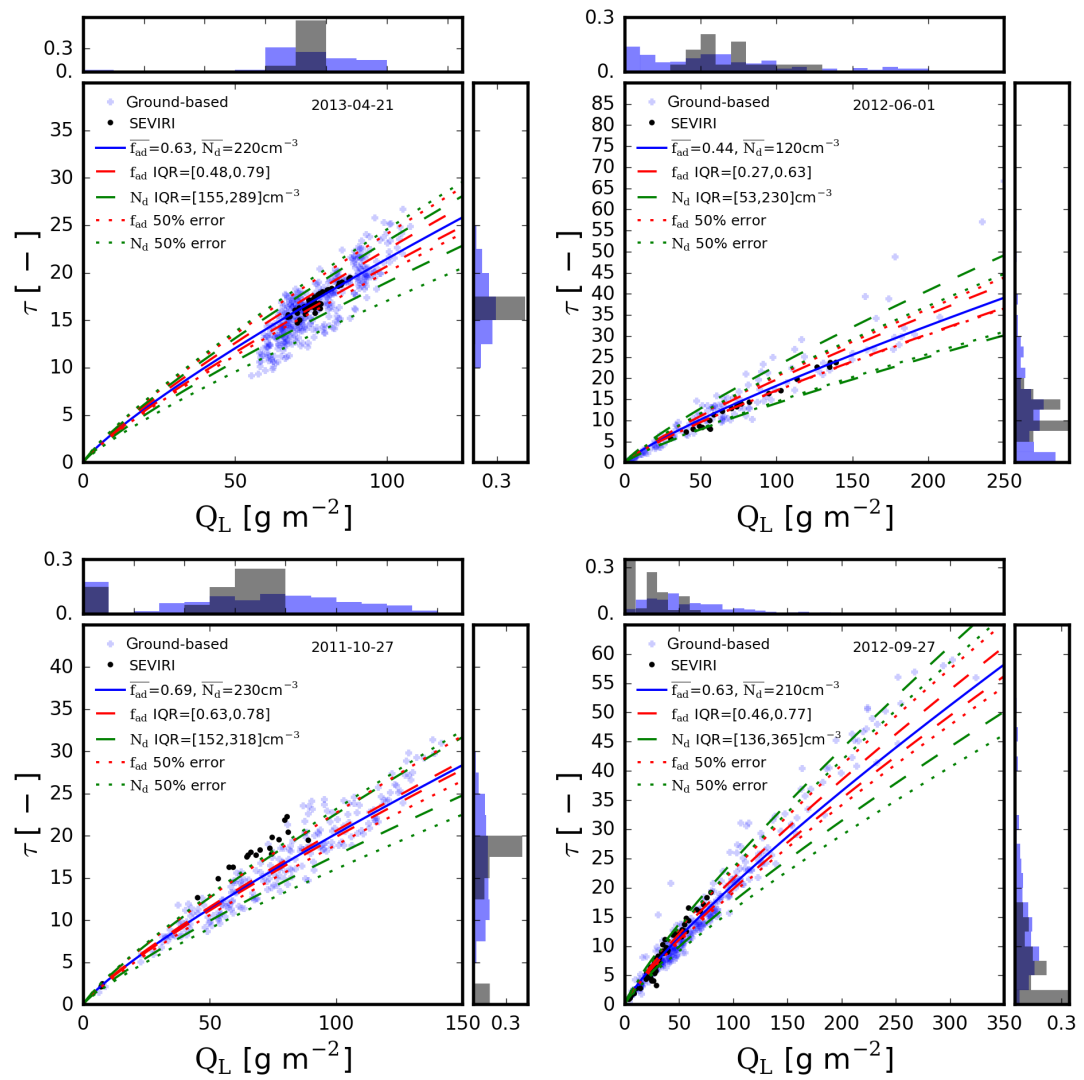

Figure 5. Relationship between $Q_{\mathrm{L}}$ and $\tau$ for the four case days (Table 2). Blue crosses represent the LACROS observations for the case day, black dots the SEVIRI observations. The solid blue line represents the relationship between $\tau$ and $Q_{\mathrm{L}}$ for the median $f_{\text {ad }}$ and $N_{\mathrm{d}}$ of the LACROS observations. Uncertainty estimates of $\tau$ as a function of $Q_{\mathrm{L}}$ is given in terms of temporal variability using the IQR of the time series (dashed), and as $50 \%$ relative uncertainty in $N_{\mathrm{d}}$ and $f_{\mathrm{ad}}$ (dotted). Furthermore the histograms of ground-based and SEVIRI observations are shown on each axis in the same colours as stated before.

height $Z$ cross section on 27 September 2012 between 11:00 and 15:00 UTC a larger number of cloud gaps can be seen, which could explain why the subpixel surface contamination plays a larger role than on 1 June 2012. The Cloudnet observations on 27 September 2012 show rapid changes of $Q_{\mathrm{L}}$ with peaks around $400 \mathrm{~g} \mathrm{~m}^{-2}$ and cloud free periods. The observed larger deviations of SEVIRI found on 27 October 2011 are likely due to low values $(<5 \mu \mathrm{m})$ of effective radius in the KNMI-CPP retrieval. These are likely a result of the unfavourable viewing conditions with a large solar zenith angle $\left(>60^{\circ}\right)$ under relative azimuth angles close to $180^{\circ}$ around noon for this case, for which Roebeling et al. (2006) pointed out the low precision of the retrieval. These values are filtered out following Roebeling et al. (2008a), but the remaining points might also be affected by the same issue.

To highlight the importance of considering the actual $f_{\text {ad }}$ for the retrieval process, we calculated $\tau$ (Eq. 7) from the ground-based observations following the radar-radiometer approach with $f_{\mathrm{ad}}=1$ and with the ground-obtained $f_{\mathrm{ad}}$. Afterwards we compare it to the satellite-retrieved values.
Applying $f_{\text {ad }}=1$ the mean difference in optical depth is increased from 2.3 to 8.5 on 21 April 2013, and is also higher for the other cases (see Table 6).

The distribution of differences between SEVIRI and ground-based $\tau$ for the 2012 and 2013 sample of low-level, homogeneous, liquid clouds is presented in Fig. 4b. As for $Q_{\mathrm{L}}$ there is a distinct peak around zero with negligible bias, but a considerable standard deviation of 16 . This shows that on average the agreement between satellite and ground-based $\tau$ is reasonable, considering the number of uncertainties in the retrieval as well as uncertainties due to parallax, collocation, and spatial resolution. Those uncertainties will be discussed in more detail in the following sections.

\subsection{Ground-based uncertainties}

The radar-radiometer retrieval depends upon the observations of $Q_{\mathrm{L}}, H$, and $Z(z)$. Also the choice of the mixing model is able to change the retrieved quantities, but Boers et al. (2006) comes to the conclusion that this effect is small. $N_{\mathrm{d}}$ depends further on $k_{6}$, which only depends on the width of the DSD (see Eq. 11 in Appendix A). 
Table 6. Mean difference of $\tau$ between SEVIRI and LACROS for each case, when $f_{\text {ad }}$ as obtained from the ground-based observations is applied and $f_{\mathrm{ad}}$ is considered constantly 1.0 .

\begin{tabular}{lcc}
\hline Date & $\tau_{\text {SEVIRI }}-\tau_{\text {LACROS }}\left(f_{\text {ad }}=f_{\text {ad }}^{\text {LACROS }}\right)$ & $\overline{\tau_{\text {SEVIRI }}-\tau_{\text {LACROS }}\left(f_{\text {ad }}=1\right)}$ \\
\hline 21 Apr 2013 & 2.3 & 8.5 \\
27 Oct 2011 & 3.6 & 6.6 \\
27 Sep 2012 & 7.9 & 10.9 \\
1 Jun 2012 & 9.3 & 12.8 \\
\hline
\end{tabular}

We take two typical cloud profiles from our observations. For those cloud profiles we evaluate the sensitivity of the retrieved $N_{\mathrm{d}}$ to the uncertainties of the input parameters based on Brandau et al. (2010). In Table 3 we list the sensitivities to each input parameter when the other parameters are kept constant.

For $Z(z)$ we follow Brandau et al. (2010) and assume an uncertainty range of $\pm 2 \mathrm{dBZ}$, which would represent a calibration bias constant with height. Drizzle does have a strong influence on Z, (e.g. Battan, 1973; Löhnert et al., 2003). Errors of 30-60\% have to be anticipated for $q_{\mathrm{L}}$ profile retrievals. Those retrieval approaches are based on very similar principles as the radar-radiometer retrieval method (Löhnert et al., 2001). In our study we filtered out drizzling profiles as well as possible. For the four case days $r_{\mathrm{e}}$ observed from satellites near cloud top lies clearly below the value of $14 \mu \mathrm{m}$ which was suggested by Rosenfeld et al. (2012) as the threshold for drizzle/rain forming clouds. The maximum of $Z(z)$ in each profile also did not exceed $-20 \mathrm{dBZ}$, which is commonly taken as a drizzle threshold (Rémillard et al., 2013; Mace and Sassen, 2000). We cannot totally rule out the possibility that few larger droplets were present, to which $Z$ is very sensitive. For the uncertainty of $H$, we assume $\pm 60 \mathrm{~m}$. For $Q_{\mathrm{L}}$ we assume a typical uncertainty of $\pm 25 \mathrm{~g} \mathrm{~m}^{-2}$ given microwave radiometer observations. The width of the DSD for continental clouds exhibits a large spread of values in literature as can be seen in Miles et al. (2000). If we consider the maximum range of observations, the effective variance $v$ of the gamma size distribution could take values between 0.043 up to 0.2 ( $k_{2}=0.87$ and $k_{2}=0.48$, respectively). For the standard retrieval we assume $v=0.1\left(k_{2}=0.72\right)$.

$N_{\mathrm{d}}$ is most sensitive to the assumption about the width of the DSD, especially to changes in the range of smaller values of the effective variance. This can be understood as $N_{\mathrm{d}} \propto k_{6}$ and $k_{6}$ is a monotonically decreasing function of the effective variance. For higher values of $v$ the other uncertainty contributions are equally or even more important. Since the real DSD is usually unknown, it is difficult to estimate the actual uncertainty when assuming $v=0.1$. From our cases we find that the uncertainty in $Q_{\mathrm{L}}$ might be more important than the uncertainty in radar reflectivity. Both can result in more than $50 \%$ relative uncertainty for the retrieval of $N_{\mathrm{d}}$.

As can be seen from Eq. (7), the optical depth $\tau$ is sensitive to the same input parameters as $N_{\mathrm{d}}$, but also depends on $f_{\text {ad }}$.
Therein the combined uncertainty of $Q_{\mathrm{L}}$ and $H$ is reflected. From Table 3 we find that $\tau$ is most sensitive to uncertainties in $Q_{\mathrm{L}}$, especially for observed low values of $Q_{\mathrm{L}}$. In contrast to $N_{\mathrm{d}}$, it is not as sensitive to the assumption about the width of the DSD. While for $N_{\mathrm{d}}$ the uncertainty in the low-range of $v$ is above $100 \%$, it is below $20 \%$ for $\tau$. Since the natural variability of DSDs is large and difficult to constrain without in situ observations, $\tau$ turns out to be a more stable quantity for contrasting to other observation, as already suggested by Brandau et al. (2010).

In Fig. 5 we present the uncertainty of $\tau$ as a function of $Q_{\mathrm{L}}$, based on the median observations from the groundbased time series. We use a representative average of $N_{\mathrm{d}}$ over the whole time period and investigate the effect of its temporal variability on the retrieved $\tau$.

Recognizing the difficulty in retrieving $N_{\mathrm{d}}$ from the $3 \mathrm{rd}$ and 6th moments, Frisch et al. (2002) used a climatological mean value for $N_{\mathrm{d}}$ in order to retrieve $r_{\mathrm{e}}$. They reported an average $N_{\mathrm{d}}$ of $212 \pm 107 \mathrm{~cm}^{-3}$ at the Southern Great Plains site for continental clouds, which is similar to the median value found for our example cases in Fig. 5. We see that assuming a $50 \%$ uncertainty for both, $N_{\mathrm{d}}$ and $\tau$, results in an increasing uncertainty of $\tau$ with $Q_{\mathrm{L}}$, with the uncertainty due to $\Delta N_{\mathrm{d}}$ being slightly larger, although $\Delta f_{\text {ad }}$ cannot be neglected.

\subsection{Satellite uncertainties}

\subsubsection{Uncertainties of $N_{\mathrm{d}}$ and $H$}

Since $N_{\mathrm{d}}$ is obtained with the sub-adiabatic model using Eq. (10), it depends on the uncertainties of $\tau$ and $r_{\mathrm{e}}$, but also on $f_{\text {ad }}, k_{2}$ and $\Gamma_{\text {ad }}$.

Roebeling et al. (2008a) reported a $150 \mathrm{~cm}^{-3}$ error for optically thick clouds $(\tau>20)$ resulting from a $10 \%$ error in $\tau$. The absolute error of $N_{\mathrm{d}}$ increases with increasing $\tau$ assuming a constant error in $r_{\mathrm{e}} . N_{\mathrm{d}}$ is also very uncertain for values of $r_{\mathrm{e}}<8 \mu \mathrm{m}$. Han et al. (1994) found that cases with $r_{\mathrm{e}}<5 \mu \mathrm{m}$ are rare compared to typical value of $10 \mu \mathrm{m}$ for liquid clouds. Roebeling et al. (2008a) argue that those should not be considered due to the large uncertainty.

If the individual errors are assumed to be normally distributed, the relative errors of $N_{\mathrm{d}}$ and $H$ are given by the 
following:

$$
\begin{aligned}
& \left(\frac{\Delta N_{\mathrm{d}}}{N_{\mathrm{d}}}\right)^{2}= \\
& \left(\frac{\Delta k_{2}}{k_{2}}\right)^{2}+\left(\frac{\Delta \Gamma_{\mathrm{ad}}}{2 \Gamma_{\mathrm{ad}}}\right)^{2}+\left(\frac{\Delta f_{\mathrm{ad}}}{2 f_{\mathrm{ad}}}\right)^{2} \\
& \quad+\left(\frac{\Delta \tau}{2 \tau}\right)^{2}+\left(\frac{5 \Delta r_{\mathrm{e}}}{2 r_{\mathrm{e}}}\right)^{2}
\end{aligned}
$$

and

$$
\begin{aligned}
& \left(\frac{\Delta H}{H}\right)^{2}= \\
& \left(\frac{\Delta \Gamma_{\mathrm{ad}}}{2 \Gamma_{\mathrm{ad}}}\right)^{2}+\left(\frac{\Delta f_{\mathrm{ad}}}{2 f_{\mathrm{ad}}}\right)^{2}+\left(\frac{\Delta \tau}{2 \tau}\right)^{2}+\left(\frac{\Delta r_{\mathrm{e}}}{2 r_{\mathrm{e}}}\right)^{2} .
\end{aligned}
$$

Uncertainties of $\tau$ and $r_{\mathrm{e}}$ stem from the assumption of plane-parallel vertical-uniform cloud layers, partially covered cloud pixels (Zinner and Mayer, 2006), 3-D effects (Loeb and Coakley, 1998), and large solar zenith angles (Roebeling et al., 2008a). Uncertainties in $r_{\mathrm{e}}$ further arise from its vertical profile. The use of different channels results in discrepancies in $r_{\mathrm{e}}$. MODIS uses a channel centred at $2.1 \mu \mathrm{m}$, while SEVIRI uses $1.6 \mu \mathrm{m}$ for the standard retrieval. From MODIS, additional $r_{\mathrm{e}}$ retrievals from channels at 1.6 and $3.7 \mu \mathrm{m}$ are available. Theoretically, the $3.7-\mu \mathrm{m}$ channel should represent $r_{\mathrm{e}}$ closer to the cloud top for adiabatic clouds, while the 2.1- and 1.6- $\mu$ m channels receive the main signal from deeper layers within the cloud. Cloud observations do not always show an increase of $r_{\mathrm{e}}$ from channel $1.6 \mu \mathrm{m}$ over 2.1 to $3.7 \mu \mathrm{m}$ as is expected for plane-parallel, adiabatic clouds (Platnick, 2000; King et al., 2013). In this study we estimate the uncertainties in passive satellite $\tau$ and $r_{\mathrm{e}}$ with $10 \%$ following Roebeling et al. (2008a) (SEVIRI) and following Platnick and Valero (1995) (MODIS), although uncertainties are probably larger for unfavourable conditions (large solar zenith angles, broken clouds).

For $\Delta f_{\text {ad }}$ we assume a relative error of $35 \%$ considering a constant $f_{\text {ad }}=0.6$ and its variability $(0.22)$ as obtained from 2-year LACROS observations. For comparison, Janssen et al. (2011) assumed an uncertainty in $f_{\text {ad }}$ of 0.3 . This resulted in a numerically evaluated error of around $26 \%$ considering typical values of $r_{\mathrm{e}}$ and $\tau$.

Janssen et al. (2011) estimated the uncertainty of $k_{2}$ to be negligible (around $3 \%$ ) for $N_{\mathrm{d}}<100 \mathrm{~cm}^{-3}$, following Boers et al. (2006). Bennartz (2007) used a variability of $k_{2}=0.8 \pm 0.1$ in a global study, which results in a relative uncertainty of $12.5 \%$. Brenguier et al. (2011) found a similar mean value for 33 cases of stratocumulus and cumulus clouds with an even smaller variability, even slightly lower than the variability in Martin et al. (1994). Therefore $12.5 \%$ might be seen as an upper uncertainty limit for $k_{2}$.

By considering the whole seasonal variability of cloud base temperature, Janssen et al. (2011) obtained an error of
$24 \%$ for $\Gamma_{\mathrm{ad}}(T, p)$. In our study $\Gamma_{\mathrm{ad}}$ has a smaller contribution to those uncertainties due to the fact that we are using model data to gain more reliable information about cloud base temperature and pressure instead of considering a constant value of $\Gamma_{\text {ad }}$ as in, e.g. Quaas et al. (2006). If we compare $\Gamma_{\text {ad }}$ calculated from satellite cloud top temperature and pressure with the one calculated from cloud base values observed from ground we find an uncertainty of $15 \%$ considering the four case days. As we see deviations in the cloud top height, we believe that this uncertainty can be mainly attributed to incorrect satellite estimates of cloud top temperature and pressure.

Janssen et al. (2011) state for satellite retrievals of $N_{\mathrm{d}}$ (and also $H_{\mathrm{ad}}$ ) that $f_{\mathrm{ad}}$ and $\Gamma_{\mathrm{ad}}$ are the most important uncertainty factors. Considering our uncertainty estimates, the largest contribution to the uncertainty of $N_{\mathrm{d}}$ is given by the relative uncertainty of $r_{\mathrm{e}}(25 \%)$, followed by $f_{\mathrm{ad}}(18 \%), k_{2}(12.5 \%)$, $\Gamma_{\text {ad }}(7.5 \%)$ and $\tau(5 \%)$. Considering the error propagation of $H$, assuming the same errors as for $N_{\mathrm{d}}$, we find the largest uncertainty due to $f_{\text {ad }}$ with $17.5 \%$, followed by $\Gamma_{\text {ad }}(7.5 \%)$ and $\tau(5 \%)$ and $r_{\mathrm{e}}(5 \%)$.

The importance of $r_{\mathrm{e}}$ for the retrieval of $N_{\mathrm{d}}$ from passive satellite imagers has already been pointed out by previous studies. Those were mainly based on observations from MODIS (Painemal and Zuidema, 2010, 2011; Ahmad et al., 2013; Zeng et al., 2014) and report a high bias of MODIS $r_{\mathrm{e}}$, especially for broken clouds (Marshak et al., 2006). Painemal and Zuidema (2010) also state that the choice of the other parameters in the retrieval (namely $k_{2}, \Gamma_{\mathrm{ad}}$ ) is able to compensate for this effect so that still a good agreement between MODIS retrieved and in situ values could be achieved. As mentioned before, for our study we focused on the intercomparison of $\tau$ instead of $N_{\mathrm{d}}$, since the ground-based retrieval of $\tau$ is less sensitive to the required assumptions.

\subsubsection{Uncertainties due to spatial resolution}

To investigate the effect of spatial resolution, we use collocated MODIS and SEVIRI observations. We use the products of MODIS at $1 \mathrm{~km}$ spatial resolution. We re-project all MODIS pixels to the $3 \times 3$ SEVIRI pixels so that both instruments cover the same area. We then average the MODIS $1 \mathrm{~km}$ resolution data to SEVIRI's spatial resolution $(4 \mathrm{~km} \times 6 \mathrm{~km})$. In a further step we average a $3 \times 3$ pixel field from SEVIRI and the MODIS pixels at original resolution and calculate their standard deviation. In this way we tried to use MODIS to account for SEVIRI's subpixel variability, while neglecting deviations due to the differences of both instruments and retrievals. In Fig. 6 the results for (a) the inhomogeneous case at 1 June 2012 and (b) the homogeneous case at 21 April 2013 are shown. For the inhomogeneous case we can clearly see the large spread of MODIS $\tau$ values, which is reduced to a similar range as for SEVIRI $\tau$ when averaged to the same spatial resolution. The spread of $\tau$ is found larger than for $r_{\mathrm{e}}$. For the homogeneous case 

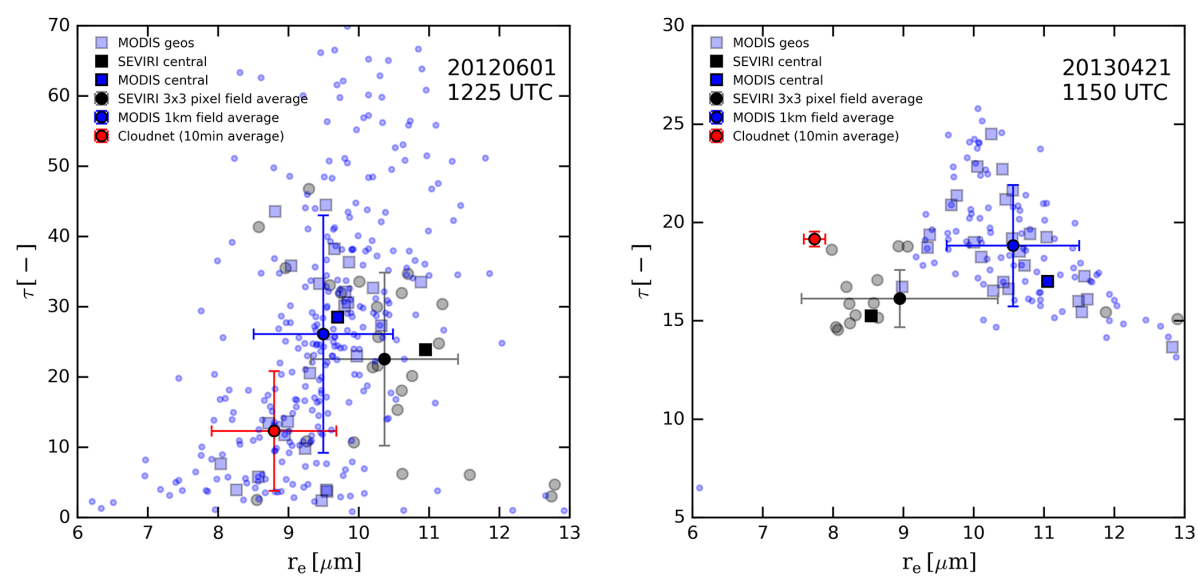

Figure 6. Effect of spatial resolution by comparing MODIS and SEVIRI observations for two timesteps: (a) inhomogeneous case, 1 June 2012 at 12:25 UTC, (b) homogeneous case, 21 April 2013 at 11:50 UTC. SEVIRI values are shown in black, MODIS values in blue and groundbased ones in red. The closest pixel (central) to LACROS is shown as a dark square. Field averages from the sensors original resolution are given as dots. For MODIS also the average to SEVIRI resolution is presented (MODIS geos, light blue square). Also the standard deviation is shown together with the averages in terms of error bars.

the spread is smaller. Differences between MODIS and SEVIRI after averaging are in a similar range for both cases. When comparing averaged data, MODIS and SEVIRI show similar results for both cases. However, the differences, especially in terms of $r_{\mathrm{e}}$ can be of the same magnitude than those to ground-retrieved values. There is considerable difference when taking either the closest pixel to the ground-based location or the spatially averaged value, while the closest pixel does not necessarily result in a better agreement with the ground-based value (Fig. 6). Therefore we can conclude that especially for inhomogeneous cases, the sub-pixel variability introduces an important additional uncertainty factor.

\section{Summary and conclusions}

In this work, we aimed to evaluate the consistency and limitations of our ground-based and satellite cloud retrieval products which are typically used to quantify aerosol-cloud interactions (ACI). We used a 2-year data set with four selected case studies.

Cloud properties have been used previously for diagnosing ACI and specifically the first indirect aerosol effect from both ground-based supersites, (e.g. Feingold et al., 2003) as well as geostationary passive satellite observations, (e.g. Bréon et al., 2002). The sub-adiabatic cloud model as a conceptional tool is commonly applied and modified using an adiabatic factor $f_{\text {ad }}$ to account for entrainment within the cloud.

Based on cloud geometric depths obtained from the combination of ground-based cloud radar and ceilometer, and liquid water path from a microwave radiometer, we demonstrated that for a 2-year data set, neither the assumption of an adiabatic cloud nor the assumption of a temporally constant $f_{\text {ad }}$ is fulfilled (mean $f_{\text {ad }}=0.63 \pm 0.22$ ).
As $f_{\text {ad }}$ is required to estimate key quantities for ACI studies, but cannot be obtained from passive satellite observations within a sufficient uncertainty range, an independent method to estimate $f_{\text {ad }}$, and thus the influence of mixing, would be highly desirable for global-scale analyses. We were able to support previous findings which reported that thinner clouds are closer to adiabaticity (Min et al., 2012) as well are clouds that show upward motion at the cloud base (Schmidt et al., 2014).

To investigate ACIs from passive satellites the cloud droplet number concentration $N_{\mathrm{d}}$ is widely used as a key parameter. An intercomparison with ground-retrieved values is complicated as it turns out that its retrieval from a groundbased radar-radiometer approach is very sensitive to assumptions about the width of the DSD and the radar calibration. The $N_{\mathrm{d}}$ retrieval from radar is poorly posed because of the moment disparity and the potential instability of the ratio in Eq. (11) as pointed out by Frisch et al. (2002). Retrieved values of $N_{\mathrm{d}}$ can change by more than $135 \%$ just due to wrong assumptions made for the width of the DSD. From passive satellite we find the main sensitivity to uncertainties in the effective radius. We conclude that neither the ground-based nor satellite-based cloud retrieved properties used here allow to obtain a robust instantaneous estimate of $N_{\mathrm{d}}$, which complicates their use for the study of ACIs.

We demonstrated that cloud optical depth $\tau$ from groundbased radar-radiometer retrievals is less sensitive to the assumptions about the DSD and is therefore better suited to investigate ACIs, consistent with the conclusions of Brandau et al. (2010). It is most sensitive to uncertainties in the liquid water path (changes of up to $50 \%$ for an uncertainty of $25 \mathrm{~g} \mathrm{~m}^{-2}$ are possible). 
Given an independent retrieval of $\tau$, e.g. from MFRSR retrievals (Min and Duan, 2005), and information such as radar Doppler velocity (Rémillard et al., 2013), should give further options for validation. Applying such additional observations in an optimal estimation scheme might give the opportunity to better constrain the retrieved $N_{\mathrm{d}}$. Also the application of cloud radar scanning capabilities together with radiance zenith measurements might improve the retrieval (Fielding et al., 2014). For validation of those $N_{\mathrm{d}}$ retrievals accompanying in situ measurements are required.

Instantaneous comparisons of $\tau$ between space and ground may result in large differences, especially for broken cloud conditions and unfavourable viewing conditions. Applying spatial and temporal averaging and subsampling to rather homogeneous, liquid clouds leads to a reasonable agreement in $\tau$ for a majority of observations during a 2-year period at LACROS, especially considering the large number of assumptions and uncertainties.

Besides the retrieval uncertainties, differences in spatial resolution affect the comparison not only between space and ground observations, but also between space-based instruments of different resolution and viewing angles (i.e. SEVIRI, MODIS). We highlighted, that especially for inhomogeneous cases, sub-pixel variability is an important uncertainty factor, but that averaging does not necessarily result in a better agreement to ground-based observations than taking the closest pixel to the location. To generalize such results more collocated MODIS, SEVIRI and ground-based observations need to be examined.
Given the network of Cloudnet/ACTRIS in central Europe this offers the opportunity to investigate the climatology of $f_{\text {ad }}$ and investigate its regional, seasonal or synoptical dependency in further studies.

With the upcoming Meteosat Third Generation (MTG) satellite (Stuhlmann et al., 2005) a higher spatial resolution of cloud products will be available and should therefore mitigate issues due to spatial resolution for the geostationary perspective. Also the sounder capabilities of MTG should give new opportunities, e.g. to overcome problems of cloud geometrical depth retrievals from passive satellites by using additional information from the oxygen A-band following the method as outlined by, e.g. Yang et al. (2013), Fischer et al. (1991) and therefore might give the possibility to obtain $f_{\text {ad }}$ over a larger domain. 


\section{Appendix A}

To obtain the factors $k_{2}$ and $k_{6}$ in the sub-adiabatic cloud model a gamma size distribution is assumed in the form of (Hansen and Travis, 1974):

$$
\begin{aligned}
\eta(r) & =A r^{\beta} \exp -\Lambda r \\
& =\frac{\eta_{0}}{\Gamma\left(\frac{1-2 v}{v}\right) r_{\mathrm{e}} v^{\frac{1-2 v}{v}}}\left(\frac{r}{r_{\mathrm{e}}}\right)^{\frac{(1-3 v)}{v}} \exp \left(-\frac{r}{r_{\mathrm{e}} v}\right)
\end{aligned}
$$

with

$$
\begin{aligned}
\beta & =\frac{1-3 v}{v} \\
\Lambda & =\frac{1}{r_{\mathrm{e}} v} \\
A & =\eta_{0} \frac{\Lambda^{\beta+1}}{\Gamma(\beta+1)} .
\end{aligned}
$$

Hereby the effective radius $r_{\mathrm{e}}$, its effective variance $v$, and the total number density of droplets $\eta_{0}$ are used. $r_{\mathrm{e}}$ is defined as the third over the second moment of the DSD (Hansen and Travis, 1974) and can be linked to the mean volume radius $\left(r_{\mathrm{v}}\right)$ with the following relationship:

$r_{\mathrm{e}}^{3}=k_{2}^{-1} r_{\mathrm{v}}^{3}$.

From the gamma size distributions its $n$th moments can be derived by (Petty and Huang, 2011):

$$
\begin{aligned}
M_{\eta, n} & =A \int r^{n+\beta} \exp (-\Lambda r) \mathrm{d} r \\
& =A \frac{\Gamma(\beta+n+1)}{\Lambda^{(\beta+n+1)}} .
\end{aligned}
$$

The factor $k_{2}$ is then only a function of the width of the DSD:

$k_{2}=\frac{M_{2}(\eta)^{3}}{M_{3}(\eta)^{2}}=(1-2 v)(1-v)$.
$Z$ as proportional to the sixth moment of the DSD can be expressed as a function of $N_{\mathrm{d}}, q_{\mathrm{L}}$ and factors that depend on the width of the DSD $\left(k_{6}\right)$ (Fox and Illingworth, 1997):

$$
Z=\frac{9}{2 \pi^{2} \rho_{w}^{2}} k_{6} \frac{q_{\mathrm{L}}^{2}}{N_{\mathrm{d}}} .
$$

Similar to $k_{2}$, the factor $k_{6}$ is defined:

$$
k_{6}=\frac{M_{6}(\eta)}{M_{3}(\eta)^{2}}=\frac{(v+1)(2 v+1)(3 v+1)}{(1-2 v)(1-v)} .
$$

Integrating over $H$, we can solve the equation for $Q_{\mathrm{L}}$ :

$$
Q_{\mathrm{L}}=\left(\frac{9}{2 \pi^{2} \rho_{w}^{2}}\right)^{-\frac{1}{2}} \int \frac{1}{k_{6}(v(z))} \sqrt{N_{\mathrm{d}}(z)} \sqrt{Z(z)} \mathrm{d} z .
$$

In the homogeneous mixing model, $N_{\mathrm{d}}(z)$ and $v(z)$ are assumed constant with height. Rémillard et al. (2013) considers a column-averaged $N_{\mathrm{d}}$ by weighting with the square-root of $Z(z)$ :

$\int \sqrt{N_{\mathrm{d}}(z)} \mathrm{d} z=\frac{\int \sqrt{N_{\mathrm{d}}(z)} \sqrt{Z(z)} \mathrm{d} z}{\int \sqrt{Z(z)} \mathrm{d} z}=\sqrt{\overline{N_{\mathrm{d}}}}$.

Using the latter relationship, we yield a retrieval method for the column-averaged $\overline{N_{\mathrm{d}}}$ :

$\overline{N_{\mathrm{d}}}\left(Q_{\mathrm{L}}, Z, k_{6}\right)=\frac{9 k_{6} Q_{\mathrm{L}}^{2}}{2 \pi^{2} \rho_{w}^{2}\left(\int \sqrt{Z(z)} \mathrm{d} z\right)^{2}}$.

Equation (A10) can be substituted into Eqs. (6) and (7) to eliminate $N_{\mathrm{d}}$ and to obtain a ground-based estimate of $\tau$ and $r_{\mathrm{e}}$. 


\section{The Supplement related to this article is available online at doi:10.5194/acp-16-933-2016-supplement.}

Acknowledgements. The first author's work was funded by the Leipzig Graduate School on Radiation (LGS-CAR). We would like to thank the Cloudnet project (European Union Contract EVK22000-00611) for providing the ground-based cloud products, and the EUMETSAT SAFS for providing the SEVIRI cloud products, as well as the NASA's Earth-Sun System Division for providing MODIS cloud products. We further acknowledge colleagues participating in the HOPE campaign of the $\mathrm{HD}(\mathrm{CP})^{2}$ project in Jülich. We also thank our colleagues Anja Hünerbein, Andreas Macke, Fabian Senf, Johannes Quaas, and three anonymous reviewers and the editor for their helpful suggestions and comments.

Edited by: G. Feingold

\section{References}

Ackerman, A. S., Toon, O. B., Taylor, J. P., Johnson, D. W., Hobbs, P. V., and Ferek, R. J.: Effects of Aerosols on Cloud Albedo: Evaluation of Twomey's Parameterization of Cloud Susceptibility Using Measurements of Ship Tracks, J. Atmos. Sci., 57, 2684-2695, doi:10.1175/15200469(2000)057<2684:EOAOCA>2.0.CO;2, 2000.

Ahmad, I., Mielonen, T., Grosvenor, D., Portin, H., Arola, A., Mikkonen, S., Kühn, T., Leskinen, A., Juotsensaari, J., Komppula, M., Lehtinen, K., Laaksonen, A., and Romakkaniemi, S.: Long-term measurements of cloud droplet concentrations and aerosol-cloud interactions in continental boundary layer clouds, Tellus B, 65, 20138, doi:10.3402/tellusb.v65i0.20138, 2013.

Albrecht, B. A., Fairall, C. W., Thomson, D. W., White, A. B., Snider, J. B., and Schubert, W. H.: Surface-based remote sensing of the observed and the Adiabatic liquid water content of stratocumulus clouds, Geophys. Res. Lett., 17, 89-92, doi:10.1029/GL017i001p00089, 1990.

Baker, M. B., Blyth, A. M., Carruthers, D. J., Choularton, T. W., Fullarton, G., Gay, M. J., Latham, J., Mill, C. S., Smith, M. H., Stromberg, I. M., Caughey, S. J., and Conway, B. J.: Field studies of the effect of entrainment upon the structure of clouds at Great Dun Fell, Q. J. Roy. Meteor. Soc., 108, 899-916, doi:10.1002/qj.49710845810, 1982.

Battan, L. J.: Radar observation of the atmosphere, University of Chicago Press, 1973.

Bennartz, R.: Global assessment of marine boundary layer cloud droplet number concentration from satellite, J. Geophys. Res.Atmos., 112, D02201, doi:10.1029/2006JD007547, 2007.

Boers, R., Russchenberg, H., Erkelens, J., Venema, V., van Lammeren, A., Apituley, A., and Jongen, S.: Ground-Based Remote Sensing of Stratocumulus Properties during CLARA, 1996, J. Appl. Meteorol., 39, 169-181, doi:10.1175/15200450(2000)039<0169:GBRSOS>2.0.CO;2, 2000.

Boers, R., Acarreta, J. R., and Gras, J. L.: Satellite monitoring of the first indirect aerosol effect: Retrieval of the droplet concentration of water clouds, J. Geophys. Res.-Atmos., 111, D22208, doi:10.1029/2005JD006838, 2006.
Boucher, O., Randall, D., Artaxo, P., Bretherton, C., Feingold, G., Forster, P., Kerminen, V.-M., Kondo, Y., Liao, H., Lohmann, U., Rasch, P., Satheesh, S. K., Sherwood, S., Stevens, B., and Zhang, X. Y.: Clouds and Aerosols, in: Climate Change 2013: The Physical Science Basis. Contribution of Working Group I to the Fifth Assessment Report of the Intergovernmental Panel on Climate Change, edited by: Stocker, T. F., Qin, D., Plattner, G.-K., Tignor, M., Allen, S. K., Boschung, J., Nauels, A., Xia, Y., Bex, V., and Midgley, P. M., Cambridge University Press, Cambridge, United Kingdom and New York, NY, USA, 2013.

Brandau, C., Russchenberg, H., and Knap, W.: Evaluation of ground-based remotely sensed liquid water cloud properties using shortwave radiation measurements, Atmos. Res., 96, 366377, doi:10.1016/j.atmosres.2010.01.009, 2010.

Brenguier, J.-L., Pawlowska, H., Schüller, L., Preusker, R., Fischer, J., and Fouquart, Y.: Radiative Properties of Boundary Layer Clouds: Droplet Effective Radius versus Number Concentration, J. Atmos. Sci., 57, 803-821, doi:10.1175/15200469(2000)057<0803:RPOBLC>2.0.CO;2, 2000.

Brenguier, J.-L., Burnet, F., and Geoffroy, O.: Cloud optical thickness and liquid water path - does the $k$ coefficient vary with droplet concentration?, Atmos. Chem. Phys., 11, 9771-9786, doi:10.5194/acp-11-9771-2011, 2011.

Bréon, F.-M., Tanré, D., and Generoso, S.: Aerosol Effect on Cloud Droplet Size Monitored from Satellite, Science, 295, 834-838, doi:10.1126/science.1066434, 2002.

Cahalan, R. F., Ridgway, W., Wiscombe, W. J., Bell, T. L., and Snider, J. B.: The Albedo of Fractal Stratocumulus Clouds, J. Atmos. Sci., 51, 2434-2455, doi:10.1175/15200469(1994)051<2434:TAOFSC>2.0.CO;2, 1994.

Christensen, M. W. and Stephens, G. L.: Microphysical and macrophysical responses of marine stratocumulus polluted by underlying ships: Evidence of cloud deepening, J. Geophys. Res.Atmos., 116, D03201, doi:10.1029/2010JD014638, 2011.

Deneke, H., Knap, W., and Simmer, C.: Multiresolution analysis of the temporal variance and correlation of transmittance and reflectance of an atmospheric column, J. Geophys. Res., 114, D17206, doi:10.1029/2008JD011680, 2009.

Derrien, M.: Algorithm theoretical basis document for cloud products (cma-pge01 v3.2, ct-pge02 v2.2, ctth-pge03 v2.2), Tech. rep., SAFNWC, 2012.

Derrien, M., Gléau, H., Daloze, J.-F., and Haeffelin, M.: Validation of SAFNWC/MSG cloud products with one year of SEVIRI data, in: 2005 EUMETSAT Meteorological Satellite Conference, pp. 95-103, 2005.

Dong, X., Ackerman, T. P., Clothiaux, E. E., Pilewskie, P., and Han, Y.: Microphysical and radiative properties of boundary layer stratiform clouds deduced from ground-based measurements, J. Geophys. Res.-Atmos., 102, 23829-23843, doi:10.1029/97JD02119, 1997.

Dong, X., Mace, G. G., Minnis, P., Smith, W. L., Poellot, M., Marchand, R. T., and Rapp, A. D.: Comparison of Stratus Cloud Properties Deduced from Surface, GOES, and Aircraft Data during the March 2000 ARM Cloud IOP, J. Atmos. Sci., 59, 3265-3284, doi:10.1175/15200469(2002)059<3265:COSCPD>2.0.CO;2, 2002.

Feingold, G., Eberhard, W. L., Veron, D. E., and Previdi, M.: First measurements of the Twomey indirect effect using 
ground-based remote sensors, Geophys. Res. Lett., 30, 1287, doi:10.1029/2002GL016633, 2003.

Fielding, M. D., Chiu, J. C., Hogan, R. J., and Feingold, G.: A novel ensemble method for retrieving properties of warm cloud in 3-D using ground-based scanning radar and zenith radiances, J. Geophys. Res.-Atmos., 119, 10912-10930, doi:10.1002/2014JD021742, 2014.

Fischer, J., Cordes, W., Schmitz-Peiffer, A., Renger, W., and Mörl, P.: Detection of Cloud-Top Height from Backscattered Radiances within the Oxygen A Band. Part 2: Measurements, J. Appl. Meteorol., 30, 1260-1267, doi:10.1175/15200450(1991)030<1260:DOCTHF>2.0.CO;2, 1991.

Flentje, H., Heese, B., Reichardt, J., and Thomas, W.: Aerosol profiling using the ceilometer network of the German Meteorological Service, Atmos. Meas. Tech. Discuss., 3, 3643-3673, doi:10.5194/amtd-3-3643-2010, 2010.

Fox, N. I. and Illingworth, A. J.: The Retrieval of Stratocumulus Cloud Properties by Ground-Based Cloud Radar, J. Appl. Meteorol., 36, 485-492, doi:10.1175/15200450(1997)036<0485:TROSCP>2.0.CO;2, 1997.

Frisch, A. S., Fairall, C. W., and Snider, J. B.: Measurement of Stratus Cloud and Drizzle Parameters in ASTEX with a Ka-Band Doppler Radar and a Microwave Radiometer, J. Atmos. Sci., 52, 2788-2799, doi:10.1175/15200469(1995)052<2788:MOSCAD>2.0.CO;2, 1995.

Frisch, S., Shupe, M., Djalalova, I., Feingold, G., and Poellot, M.: The Retrieval of Stratus Cloud Droplet Effective Radius with Cloud Radars, J. Atmos. Ocean. Tech., 19, 835-842, doi:10.1175/1520-0426(2002)019<0835:TROSCD>2.0.CO;2, 2002.

George, R. C. and Wood, R.: Subseasonal variability of low cloud radiative properties over the southeast Pacific Ocean, Atmos. Chem. Phys., 10, 4047-4063, doi:10.5194/acp-10-4047-2010, 2010.

Greuell, W. and Roebeling, R. A.: Toward a Standard Procedure for Validation of Satellite-Derived Cloud Liquid Water Path: A Study with SEVIRI Data, J. Appl. Meteorol. Clim., 48, 15751590, doi:10.1175/2009JAMC2112.1, 2009.

Han, Q., Rossow, W. B., and Lacis, A. A.: Near-Global Survey of Effective Droplet Radii in Liquid Water Clouds Using ISCCP Data, J. Climate, 7, 465-497, doi:10.1175/15200442(1994)007<0465:NGSOED>2.0.CO;2, 1994.

Han, Q., Rossow, W. B., Chou, J., and Welch, R. M.: Global variation of column droplet concentration in low-level clouds, Geophys. Res. Lett., 25, 1419-1422, doi:10.1029/98GL01095, 1998.

Hansen, J. E. and Travis, L. D.: Light scattering in planetary atmospheres, Space Sci. Rev., 16, 527-610, 1974.

Illingworth, A. J., Hogan, R. J., O’Connor, E. J., Bouniol, D., Brooks, M. E., Delanoë, J., Donovan, D. P., Eastment, J. D., Gaussiat, N., Goddard, J. W. F., Haeffelin, M., Klein Baltink, H., Krasnov,O. A., Pelon, J., Piriou, J.-M., Protat, A., Russchenberg, H. W. J., Seifert, A., Tompkins, A. M., Van Zadelhoff, G.-J., Vinit, F., Willén, U., Wilson, D. R., and Wrench, C. L.: Cloudnet: Continuous evaluation of cloud profiles in seven operational models using ground-based observations, B. Am. Meteorol. Soc., 88, 883-898, 2007.

Janssen, R. H. H., Ganzeveld, L. N., Kabat, P., Kulmala, M., Nieminen, T., and Roebeling, R. A.: Estimating seasonal variations in cloud droplet number concentration over the boreal forest from satellite observations, Atmos. Chem. Phys., 11, 7701-7713, doi:10.5194/acp-11-7701-2011, 2011.

Kim, B.-G., Miller, M. A., Schwartz, S. E., Liu, Y., and Min, Q.: The role of adiabaticity in the aerosol first indirect effect, J. Geophys. Res.-Atmos., 113, D05210, doi:10.1029/2007JD008961, 2008.

King, N. J., Bower, K. N., Crosier, J., and Crawford, I.: Evaluating MODIS cloud retrievals with in situ observations from VOCALS-REx, Atmos. Chem. Phys., 13, 191-209, doi:10.5194/acp-13-191-2013, 2013.

Krzywinski, M. and Altman, N.: Points of Significance: Visualizing samples with box plots, Nat. Meth., 11, 119-120, 2014.

Lehmann, K., Siebert, H., and Shaw, R. A.: Homogeneous and Inhomogeneous Mixing in Cumulus Clouds: Dependence on Local Turbulence Structure, J. Atmos. Sci., 66, 3641-3659, doi:10.1175/2009JAS3012.1, 2009.

Loeb, N. G. and Coakley, J. A.: Inference of Marine Stratus Cloud Optical Depths from Satellite Measurements: Does 1D Theory Apply?, J. Climate, 11, 215-233, doi:10.1175/15200442(1998)011<0215:IOMSCO>2.0.CO;2, 1998.

Löhnert, U., Crewell, S., Simmer, C., and Macke, A.: Profiling Cloud Liquid Water by Combining Active and Passive Microwave Measurements with Cloud Model Statistics, J. Atmos. Ocean. Tech., 18, 1354-1366, doi:10.1175/15200426(2001)018<1354:PCLWBC>2.0.CO;2, 2001.

Löhnert, U., Feingold, G., Uttal, T., Frisch, A. S., and Shupe, M. D.: Analysis of two independent methods for retrieving liquid water profiles in spring and summer Arctic boundary clouds, J. Geophys. Res.-Atmos., 108, 4219, doi:10.1029/2002JD002861, 2003.

Mace, G. G. and Sassen, K.: A constrained algorithm for retrieval of stratocumulus cloud properties using solar radiation, microwave radiometer, and millimeter cloud radar data, J. Geophys. Res.Atmos., 105, 29099-29108, doi:10.1029/2000JD900403, 2000.

Marshak, A., Platnick, S., Várnai, T., Wen, G., and Cahalan, R. F.: Impact of three-dimensional radiative effects on satellite retrievals of cloud droplet sizes, J. Geophys. Res.-Atmos., 111, d09207, doi:10.1029/2005JD006686, 2006.

Martin, G. M., Johnson, D. W., and Spice, A.: The Measurement and Parameterization of Effective Radius of Droplets in Warm Stratocumulus Clouds, J. Atmos. Sci., 51, 1823-1842, doi:10.1175/1520-0469(1994)051<1823:TMAPOE>2.0.CO;2, 1994.

Martucci, G. and O'Dowd, C. D.: Ground-based retrieval of continental and marine warm cloud microphysics, Atmos. Meas. Tech., 4, 2749-2765, doi:10.5194/amt-4-2749-2011, 2011.

Martucci, G., Milroy, C., and O'Dowd, C. D.: Detection of Cloud-Base Height Using Jenoptik CHM15K and Vaisala CL31 Ceilometers, J. Atmos. Ocean. Tech., 27, 305-318, doi:10.1175/2009JTECHA1326.1, 2010.

McComiskey, A. and Feingold, G.: The scale problem in quantifying aerosol indirect effects, Atmos. Chem. Phys., 12, 1031-1049, doi:10.5194/acp-12-1031-2012, 2012.

Meerkötter, R. and Bugliaro, L.: Diurnal evolution of cloud base heights in convective cloud fields from MSG/SEVIRI data, Atmos. Chem. Phys., 9, 1767-1778, doi:10.5194/acp-9-1767-2009, 2009.

Meerkötter, R. and Zinner, T.: Satellite remote sensing of cloud base height for convective cloud fields: A case study, Geophys. Res. Lett., 34, L17805, doi:10.1029/2007GL030347, 2007. 
Miles, N. L., Verlinde, J., and Clothiaux, E. E.: Cloud Droplet Size Distributions in Low-Level Stratiform Clouds, J. Atmos. Sci., 57, 295-311, doi:10.1175/15200469(2000)057<0295:CDSDIL>2.0.CO;2, 2000.

Miller, M. A., Jensen, M. P., and Clothiaux, E. E.: Diurnal Cloud and Thermodynamic Variations in the Stratocumulus Transition Regime: A Case Study Using In Situ and Remote Sensors, J. Atmos. Sci., 55, 2294-2310, doi:10.1175/15200469(1998)055<2294:DCATVI>2.0.CO;2, 1998.

Min, Q. and Duan, M.: Simultaneously retrieving cloud optical depth and effective radius for optically thin clouds, J. Geophys. Res.-Atmos., 110, d21201, doi:10.1029/2005JD006136, 2005.

Min, Q., Joseph, E., Lin, Y., Min, L., Yin, B., Daum, P. H., Kleinman, L. I., Wang, J., and Lee, Y.-N.: Comparison of MODIS cloud microphysical properties with in-situ measurements over the Southeast Pacific, Atmos. Chem. Phys., 12, 11261-11273, doi:10.5194/acp-12-11261-2012, 2012.

Nakajima, T. and King, M. D.: Determination of the Optical Thickness and Effective Particle Radius of Clouds from Reflected Solar Radiation Measurements. Part I: Theory, J. Atmos. Sci., 47, 1878-1893, doi:10.1175/15200469(1990)047<1878:DOTOTA>2.0.CO;2, 1990.

Painemal, D. and Zuidema, P.: Microphysical variability in southeast Pacific Stratocumulus clouds: synoptic conditions and radiative response, Atmos. Chem. Phys., 10, 6255-6269, doi:10.5194/acp-10-6255-2010, 2010.

Painemal, D. and Zuidema, P.: Assessment of MODIS cloud effective radius and optical thickness retrievals over the Southeast Pacific with VOCALS-REx in situ measurements, J. Geophys. Res.-Atmos., 116, D24206, doi:10.1029/2011JD016155, 2011.

Painemal, D. and Zuidema, P.: The first aerosol indirect effect quantified through airborne remote sensing during VOCALSREx, Atmos. Chem. Phys., 13, 917-931, doi:10.5194/acp-13917-2013, 2013.

Pawlowska, H., Brenguier, J., and Burnet, F.: Microphysical properties of stratocumulus clouds, Atmos. Res., 55, 15-33, doi:10.1016/S0169-8095(00)00054-5, 2000.

Pawlowska, H., Grabowski, W. W., and Brenguier, J.-L.: Observations of the width of cloud droplet spectra in stratocumulus, Geophys. Res. Lett., 33, 119810, doi:10.1029/2006GL026841, 2006.

Petty, G. W. and Huang, W.: The Modified Gamma Size Distribution Applied to Inhomogeneous and Nonspherical Particles: Key Relationships and Conversions, J. Atmos. Sci., 68, 1460-1473, doi:10.1175/2011JAS3645.1, 2011.

Platnick, S.: Vertical photon transport in cloud remote sensing problems, J. Geophys. Res.-Atmos., 105, 22919-22935, doi:10.1029/2000JD900333, 2000.

Platnick, S. and Valero, F. P. J.: A Validation of a Satellite Cloud Retrieval during ASTEX, J. Atmos. Sci., 52, 2985-3001, doi:10.1175/1520-0469(1995)052<2985:AVOASC>2.0.CO;2, 1995.

Platnick, S., King, M. D., Ackerman, S. A., Menzel, W. P., Baum, B. A., Riédi, J. C., and Frey, R. A.: The MODIS cloud products: Algorithms and examples from Terra, IEEE T. Geosci. Remote, 41, 459-473, 2003.

Quaas, J., Boucher, O., and Lohmann, U.: Constraining the total aerosol indirect effect in the LMDZ and ECHAM4 GCMs using MODIS satellite data, Atmos. Chem. Phys., 6, 947-955, doi:10.5194/acp-6-947-2006, 2006.
Quaas, J., Boucher, O., Bellouin, N., and Kinne, S.: Satellite-based estimate of the direct and indirect aerosol climate forcing, J. Geophys. Res.-Atmos., 113, D05204, doi:10.1029/2007JD008962, 2008.

Rémillard, J., Kollias, P., and Szyrmer, W.: Radar-radiometer retrievals of cloud number concentration and dispersion parameter in nondrizzling marine stratocumulus, Atmos. Meas. Tech., 6, 1817-1828, doi:10.5194/amt-6-1817-2013, 2013.

Roebeling, R. A., Feijt, A. J., and Stammes, P.: Cloud property retrievals for climate monitoring: Implications of differences between Spinning Enhanced Visible and Infrared Imager (SEVIRI) on METEOSAT- 8 and Advanced Very High Resolution Radiometer (AVHRR) on NOAA-17, J. Geophys. Res.-Atmos., 111, D20210, doi:10.1029/2005JD006990, 2006.

Roebeling, R. A., Placidi, S., Donovan, D., Russchenberg, H., and Feijt, A.: Validation of liquid cloud property retrievals from SEVIRI using ground-based observations, Geophys. Res. Lett., 35, L05814, doi:10.1029/2007GL032115, 2008a.

Roebeling, R. A., Deneke, H. M., and Feijt, A. J.: Validation of Cloud Liquid Water Path Retrievals from SEVIRI Using One Year of CloudNET Observations, J. Appl. Meteorol. Clim., 47, 206-222, doi:10.1175/2007JAMC1661.1, 2008b.

Rosenfeld, D., Wang, H., and Rasch, P. J.: The roles of cloud drop effective radius and LWP in determining rain properties in marine stratocumulus, Geophys. Res. Lett., 39, L13801, doi:10.1029/2012GL052028, 2012.

Saunders, R., Matricardi, M., and Brunel, P.: An improved fast radiative transfer model for assimilation of satellite radiance observations, Q. J. Roy. Meteor. Soc., 125, 1407-1425, doi:10.1002/qj.1999.49712555615, 1999.

Schmetz, J., Pili, P., Tjemkes, S., Just, D., Kerkmann, J., Rota, S., and Ratier, A.: An introduction to Meteosat Second Generation (MSG), B. Am. Meteorol. Soc., 83, 977-992, doi:10.1175/15200477(2002)083<0977:AITMSG>2.3.CO;2, 2002.

Schmidt, J., Ansmann, A., Bühl, J., Baars, H., Wandinger, U., Müller, D., and Malinka, A. V.: Dual-FOV Raman and Doppler lidar studies of aerosol-cloud interactions: Simultaneous profiling of aerosols, warm-cloud properties, and vertical wind, J. Geophys. Res.-Atmos., 119, 5512-5527, doi:10.1002/2013JD020424, 2014.

Schueller, L., Brenguier, J.-L., and Pawlowska, H.: Retrieval of microphysical, geometrical, and radiative properties of marine stratocumulus from remote sensing, J. Geophys. Res., 108, 8631, doi:10.1029/2002JD002680, 2003.

Schüller, L., Bennartz, R., Fischer, J., and Brenguier, J.-L.: An Algorithm for the Retrieval of Droplet Number Concentration and Geometrical Thickness of Stratiform Marine Boundary Layer Clouds Applied to MODIS Radiometric Observations, J. Appl. Meteorol., 44, 28-38, doi:10.1175/JAM-2185.1, 2005.

Schulz, J., Albert, P., Behr, H.-D., Caprion, D., Deneke, H., Dewitte, S., Dürr, B., Fuchs, P., Gratzki, A., Hechler, P., Hollmann, R., Johnston, S., Karlsson, K.-G., Manninen, T., Müller, R., Reuter, M., Riihelä, A., Roebeling, R., Selbach, N., Tetzlaff, A., Thomas, W., Werscheck, M., Wolters, E., and Zelenka, A.: Operational climate monitoring from space: the EUMETSAT Satellite Application Facility on Climate Monitoring (CM-SAF), Atmos. Chem. Phys., 9, 1687-1709, doi:10.5194/acp-9-1687-2009, 2009. 
Shupe, M. D.: A ground-based multisensor cloud phase classifier, Geophys. Res. Lett., 34, L22809, doi:10.1029/2007GL031008, 2007.

Stephens, G. L., Vane, D. G., Boain, R. J., Mace, G. G., Sassen, K., Wang, Z., Illingworth, A. J., O'Connor, E. J., Rossow, W. B., Durden, S. L., Miller, S. D., Austin, R. T., Benedetti, A., Mitrescu, C., and CloudSat Science Team, T.: THE CLOUDSAT MISSION AND THE A-TRAIN, B. Am. Meteorol. Soc., 83, 1771-1790, doi:10.1175/BAMS-83-12-1771, 2002.

Stuhlmann, R., Rodriguez, A., Tjemkes, S., Grandell, J., Arriaga, A., Bézy, J.-L., Aminou, D., and Bensi, P.: Plans for EUMETSAT's Third Generation Meteosat geostationary satellite programme, Adv. Space Res., 36, 975-981, doi:10.1016/j.asr.2005.03.091, 2005.

Szczodrak, M., Austin, P. H., and Krummel, P. B.: Variability of Optical Depth and Effective Radius in Marine Stratocumulus Clouds, J. Atmos. Sci., 58, 2912-2926, doi:10.1175/15200469(2001)058<2912:VOODAE>2.0.CO;2, 2001.

Turner, D. D., Vogelmann, A. M., Johnson, K., Miller, M., Austin, R. T., Barnard, J. C., Flynn, C., Long, C., McFarlane, S. A., Cady-Pereira, K., Clough, S. A., Chiu, J. C., Khaiyer, M. M., Liljegren, J., Lin, B., Minnis, P., Marshak, A., Matrosov, S. Y., Min, Q., O'Hirok, W., Wang, Z., and Wiscombe, W.: Thin Liquid Water Clouds: Their Importance and Our Challenge, B. Am. Meteorol. Soc., 88, 177-190, doi:10.1175/BAMS-88-2-177, 2007.

Twomey, S.: Pollution and the planetary albedo, Atmos. Environ., 8, 1251-1256, doi:10.1016/0004-6981(74)90004-3, 1974.
Wang, L., Qu, J. J., Xiong, X., Hao, X., Xie, Y., and Che, N.: A New Method for Retrieving Band 6 of Aqua MODIS, IEEE T. Geosci. Remote Sens., 3, 267, doi:10.1109/LGRS.2006.869966, 2006.

Warner, J.: The Water Content of Cumuliform Cloud, Tellus, 7, 449-457, doi:10.1111/j.2153-3490.1955.tb01183.x, 1955.

Winker, D. M., Vaughan, M. A., Omar, A., Hu, Y., Powell, K. A., Liu, Z., Hunt, W. H., and Young, S. A.: Overview of the CALIPSO Mission and CALIOP Data Processing Algorithms, J. Atmos. Ocean. Tech., 26, 2310-2323, doi:10.1175/2009JTECHA1281.1, 2009.

Wood, R.: Relationships between optical depth, liquid water path, droplet concentration, and effective radius in adiabatic layer cloud, University of Washington, 3, 2006.

Yang, Y., Marshak, A., Mao, J., Lyapustin, A., and Herman, J.: A method of retrieving cloud top height and cloud geometrical thickness with oxygen A and B bands for the Deep Space Climate Observatory (DSCOVR) mission: Radiative transfer simulations, J. Quant. Spectrosc. Ra., 122, 141-149, doi:10.1016/j.jqsrt.2012.09.017, 2013.

Zeng, S., Riedi, J., Trepte, C. R., Winker, D. M., and Hu, Y.-X.: Study of global cloud droplet number concentration with A-Train satellites, Atmos. Chem. Phys., 14, 7125-7134, doi:10.5194/acp14-7125-2014, 2014.

Zinner, T. and Mayer, B.: Remote sensing of stratocumulus clouds: Uncertainties and biases due to inhomogeneity, J. Geophys. Res., 111, D14209, doi:10.1029/2005JD006955, 2006. 